\title{
Sarcoidosis: A Clinical Overview from Symptoms to Diagnosis
}

\author{
Pascal Sève 1,2,*(D), Yves Pacheco ${ }^{3}$, François Durupt ${ }^{4}$, Yvan Jamilloux ${ }^{1}$, Mathieu Gerfaud-Valentin ${ }^{1}$ (D), \\ Sylvie Isaac ${ }^{5}$, Loïc Boussel ${ }^{6}$, Alain Calender ${ }^{7}$, Géraldine Androdias ${ }^{8}$, Dominique Valeyre ${ }^{9}$ and \\ Thomas El Jammal ${ }^{1}$
}

1 Department of Internal Medicine, Lyon University Hospital, 69007 Lyon, France; yvan.jamilloux@chu-lyon.fr (Y.J.); mathieu.gerfaud-valentin@chu-lyon.fr (M.G.-V.); thomas_3901@hotmail.fr (T.E.J.)

2 Université Claude Bernard Lyon 1, Research on Healthcare Performance (RESHAPE), INSERM U1290, 69007 Lyon, France

3 Faculty of Medicine, University Claude Bernard Lyon 1, F-69007 Lyon, France; yves.pacheco@univ-lyon1.fr

4 Department of Dermatology, Lyon University Hospital, 69004 Lyon, France; francois.durupt@chu-lyon.fr

5 Department of Pathology, Lyon University Hospital, 69310 Pierre Bénite, France; sylvie.isaac@chu-lyon.fr

6 Department of Radiology, Lyon University Hospital, 69004 Lyon, France; loïc.boussel@chu-lyon.fr

7 Department of Genetics, Lyon University Hospital, 69500 Bron, France; alain.calender@chu-lyon.fr

8 Department of Neurology, Service Sclérose en Plaques, Pathologies de la Myéline et Neuro-Inflammation, Hôpital Neurologique Pierre Wertheimer, Lyon University Hospital, F-69677 Bron, France; geraldine.androdias-condemine@chu-lyon.fr

9 Department of Pneumology, Assistance Publique-Hôpitaux de Paris, Hôpital Avicenne et Université Paris 13, Sorbonne Paris Cité, 93008 Bobigny, France; dominique.valeyre@aphp.fr

* Correspondence: pascal.seve@chu-lyon.fr

Citation: Sève, P.; Pacheco, Y.; Durupt, F.; Jamilloux, Y.;

Gerfaud-Valentin, M.; Isaac, S.;

Boussel, L.; Calender, A.; Androdias, G.; Valeyre, D.; et al. Sarcoidosis: A Clinical Overview from Symptoms to Diagnosis. Cells 2021, 10, 766 . https://doi.org/10.3390/cells10040766

Academic Editor: Ritva Tikkanen

Received: 5 March 2021

Accepted: 27 March 2021

Published: 31 March 2021

Publisher's Note: MDPI stays neutral with regard to jurisdictional claims in published maps and institutional affiliations.

Copyright: (c) 2021 by the authors. Licensee MDPI, Basel, Switzerland. This article is an open access article distributed under the terms and conditions of the Creative Commons Attribution (CC BY) license (https:// creativecommons.org/licenses/by/ $4.0 /)$.

\begin{abstract}
Sarcoidosis is a multi-system disease of unknown etiology characterized by the formation of granulomas in various organs. It affects people of all ethnic backgrounds and occurs at any time of life but is more frequent in African Americans and Scandinavians and in adults between 30 and 50 years of age. Sarcoidosis can affect any organ with a frequency varying according to ethnicity, sex and age. Intrathoracic involvement occurs in $90 \%$ of patients with symmetrical bilateral hilar adenopathy and/or diffuse lung micronodules, mainly along the lymphatic structures which are the most affected system. Among extrapulmonary manifestations, skin lesions, uveitis, liver or splenic involvement, peripheral and abdominal lymphadenopathy and peripheral arthritis are the most frequent with a prevalence of $25-50 \%$. Finally, cardiac and neurological manifestations which can be the initial manifestation of sarcoidosis, as can be bilateral parotitis, nasosinusal or laryngeal signs, hypercalcemia and renal dysfunction, affect less than $10 \%$ of patients. The diagnosis is not standardized but is based on three major criteria: a compatible clinical and/or radiological presentation, the histological evidence of non-necrotizing granulomatous inflammation in one or more tissues and the exclusion of alternative causes of granulomatous disease. Certain clinical features are considered to be highly specific of the disease (e.g., Löfgren's syndrome, lupus pernio, Heerfordt's syndrome) and do not require histological confirmation. New diagnostic guidelines were recently published. Specific clinical criteria have been developed for the diagnosis of cardiac, neurological and ocular sarcoidosis. This article focuses on the clinical presentation and the common differentials that need to be considered when appropriate.
\end{abstract}

Keywords: sarcoidosis; granulomatosis; cardiac sarcoidosis; neurosarcoidosis; diagnostics; differentials

\section{Introduction}

Sarcoidosis was first described by Besnier et al. in 1889 [1]. It is a multi-system disease of unknown etiology characterized by the infiltration of various organs by nonnecrotizing granulomas. Even if sarcoidosis remains a disease of unknown cause, the mechanisms underlying granuloma formation are better and better understood, including genetic susceptibility and environmental factors [2]. 
Sarcoidosis can occur regardless of ethnicity or age. However, African Americans and Scandinavians have a higher incidence of the disease than the rest of the Caucasian population. Sarcoidosis generally starts in adults under 50 years of age. About 70\% of cases occur between 25 and 40 years of age at presentation, with a second peak of incidence in women over 50 years old [3]. Its incidence is estimated to be between 2.3 and 11 per 100,000 individuals/year [4]. The estimated prevalence varies from 2.17 to 160 per 100,000 individuals. This high variability could be explained by the various diagnostic tools used in older series to define sarcoidosis and by the ethnicity of each cohort. In a well-conducted five-year study from a health maintenance organization in the United States (US), the age-adjusted annual incidence was 10.9 per 100,000 among Caucasian Americans and 35.5 per 100,000 for African Americans. The lifetime risk of sarcoidosis was estimated at $0.85 \%$ for Caucasian Americans and 2.4\% for African Americans [5].

Sarcoidosis can follow two different courses: a time-limited one (in which two-thirds of the patients evolve through a self-remitting disease within 12 to 36 months) and a chronic course (in which 10 to $30 \%$ of patients require prolonged treatment) $[3,4,6]$. Not all patients with sarcoidosis will require systemic treatment, which is often reserved for lifethreatening organ involvement (advanced pulmonary fibrosis, pulmonary hypertension, central nervous system (CNS) sarcoidosis, cardiac sarcoidosis, portal hypertension, etc.) or functional threat (severe or defacing skin disease, laryngeal involvement and/or posterior uveitis) [7]. Ethnicity (particularly African American and Afro Caribbean origins), age over 40 years at presentation, lupus pernio, chronic uveitis, sinonasal and osseous localizations, CNS involvement, cardiac involvement, severe hypercalcemia, nephrocalcinosis and radiographic stages III and IV have been associated with a poor prognosis [8]. Patients with sarcoidosis have a shorter life expectancy than the general population [9]. The mortality ratio in the sarcoidosis patient population can, for example, exceed 25 per million in African American women [10]. In Western countries, most sarcoidosis deaths are due to advanced pulmonary fibrosis leading to respiratory failure, pulmonary hypertension or both [11] and less commonly, cardiac and CNS sarcoidosis or portal hypertension [3]. In Japan, the main cause of mortality in sarcoidosis patients is cardiac involvement, which is responsible for $77 \%$ of deaths in people with sarcoidosis [12]. In addition to treatment-related mortality, less common causes of death include lymphoma and hemoptysis due to mycetoma $[10,13]$.

\section{Clinical Manifestations}

Sarcoidosis is remarkable in that it can affect any organ. Common presentations are discussed below, with an estimate of their frequency; these estimates are based on data from US, Japanese and European studies $[12,14,15]$. In older studies, up to half of the patients could have asymptomatic disease, identified on chest X-ray (CXR) performed for other reasons. Fortuitous discovery on CXR is now very rare, reported in $8.4 \%$ of patients [16,17]. General symptoms like fatigue are seen in nearly $70 \%$ of patients, sometimes at the forefront of clinical features. More than $20 \%$ of patients have peripheral lymphadenopathy involving the cervical, axillary, inguinal and epitrochlear glands. The affected lymph nodes are moderately swollen and are usually painless. Differential diagnosis should include lymphoproliferative disorders such as Hodgkin's lymphoma and infectious diseases including leishmaniasis, toxoplasmosis and tuberculosis [18].

\subsection{General Symptoms}

General symptoms are frequent in sarcoidosis [19]. For example, the prevalence of fatigue in sarcoidosis patients can reach 50 to $70 \%$ according to series [20]. Fatigue is not specific for sarcoidosis and it can be associated with different causes such as hypothyroidism, anxiety, depression, sleep apnea or active and severe inflammatory reaction [20]. A positive association was found between small fiber neuropathy and fatigue and also between dyspnea and fatigue [19]. The accurate detection of fatigue can be made with the Fatigue Assessment Scale [21]. The detection of fatigue is of utmost importance in sarcoidosis because on the one hand, fatigue is negatively related to quality of life in studies [22-25] 
and, on the other hand, the implementation of an adapted treatment can improve the patient's symptoms [20]. Concentration disturbances are also a frequently reported symptom in patients with sarcoidosis and may be due to various associated comorbidities or consequences of sarcoidosis (e.g., sleep apnea and obstructive pulmonary disease). It is assumed that systemic treatment has a positive effect on sarcoidosis-associated cognitive complaint and cognitive disorders $[19,26]$.

Other non-specific constitutional symptoms in sarcoidosis can include fever and weight loss. In most cases, fever remains low grade but can sometimes reach 39 to $40^{\circ} \mathrm{C}$ [27]. In sarcoidosis, fever can be encountered during LS. Nevertheless, fever in a patient diagnosed with granulomatosis should rise the question of differential diagnoses and especially infectious differentials (e.g., tuberculosis). Sarcoidosis can also be a cause of fever of unknown origin and should be kept in mind when facing this clinical presentation [28]. Other general symptoms may be part of the initial clinical picture of sarcoidosis, such as weight loss and night sweats [27]. Of note, patients with hepatic manifestations of sarcoidosis can present with fever, night sweats and weight loss along with anorexia [29].

\subsection{Lungs}

Respiratory symptoms are found at presentation in $30-53 \%$ of patients; cough in $27-53 \%$, dyspnea in $18-51 \%$ and chest pain in $9-23 \%$ [16,30,31]. Chronic dyspnea is most frequently seen in patients with a delayed diagnosis, such as in the $10 \%$ of patients diagnosed with sarcoidosis-related lung fibrosis [9]. Bilateral perihilar lymphadenopathy, which is most frequently mediastinal lymphadenopathy [32] and perilymphatic pulmonary nodules predominantly seen in the upper lobe are the most typical imaging findings. Scadding's classification defines five stages of sarcoidosis on a CXR (Figure 1).

This system was developed prior to computed tomography (CT) and is widely used for its prognostic value. Mediastinal lymphadenopathy, especially right paratracheal and aortopulmonary locations, are commonly observed on chest CT. Calcifications [33] of lymph nodes may occur in sarcoidosis; they are usually chalky, focal and tend to be bilateral when present [33]. Chest CT is much more sensitive than CXR for the detection of lung nodules and subtle fibrosis. Pulmonary nodules tend to be tiny, usually termed "micronodules" ranging from 2 to $5 \mathrm{~mm}$, typically located along the bronchovascular bundles, interlobular septa, interlobar fissures and subpleural regions, which constitute the "perilymphatic distribution (Figure 2A). Pulmonary fibrotic changes may be a dominant feature with typical features of architectural distortion, volume loss and bronchiectasis, which tend to predominate in the middle and upper lung zones (Figure 2B). Recently, the "dark lymph node" or the "cluster of black pearls" sign (defined by tiny round nodules each measuring 1-2 $\mathrm{mm}$ which are seen uniformly distributed throughout all or part of the lymph node) has been described as relatively specific of sarcoidosis with negative and positive predictive values of 96 and 91\%, respectively [34]. The "galaxy" sign is also highly suggestive for sarcoidosis; it consists of a large nodule, usually with irregular boundaries, surrounded by a border of tiny satellite nodules. Alveolar, pseudo-alveolar consolidations, or diffuse ground glass are rarely the cause of sarcoidosis-associated radiological abnormalities [35].

Pulmonary function tests (PFTs) results generally correlate with the overall disease process assessed on lung histological examination between patients with mild and severe disease. However, PFTs do not differentiate the influence of alveolitis, granulomas or fibrosis [36]. PFT also reflect the impact of sarcoidosis at the pulmonary level but are not always correlated with radiographic staging (i.e., overlaps are not infrequent). The restriction of the lung volumes, particularly forced vital capacity (FVC), is the most common finding at spirometry and tends to be more frequent and marked from radiographic stage I to stage IV but with significant overlap at an individual level. Forced expiratory volume in one second (FEV1)/FVC ratio can be decreased [37] either in the case of significant bronchial distortion and stenosis due to pulmonary fibrosis [38] or to diffuse bronchial granulomatosis [39], proximal endobronchial stenosis [40,41], bronchial compression due to lymphadenopathy, granulomatous bronchiolitis or bronchial hyperreactivity [42]. The 
mechanisms involved are often multiple in the same patient and can be clarified by the combined use of CT, PFTs and bronchoscopy. Diffusing capacity of the lung for carbon monoxide (DLCO) is predictive of pulmonary vascular involvement when its value is more importantly decreased than that of FVC. Low DLCO value can also be the result of diffuse parenchymal involvement or alveolitis. PFTs have a prognostic value. The Composite Physiologic Index (CPI) is a composite score calculated with disease extent on CT, DLCO, FVC and FEV1 values and is more closely correlated to disease extent in idiopathic pulmonary fibrosis than isolated parameters from PFTs such as FVC and DLCO [43]. CPI is also more correlated to disease extent than FVC because of DLCO implementation in the calculated index. The CPI when $>40$ is predictive of mortality in sarcoidosis patients [44]. Six-minute walk test (6MWT) distance is often reduced and correlated with FVC decrease and results of St George's respiratory questionnaire [22]. Cardiopulmonary exercise testing helps to understand the underlying mechanism of dyspnea of uncertain origin, particularly when spirometry and DLCO are within normal ranges [45-49].

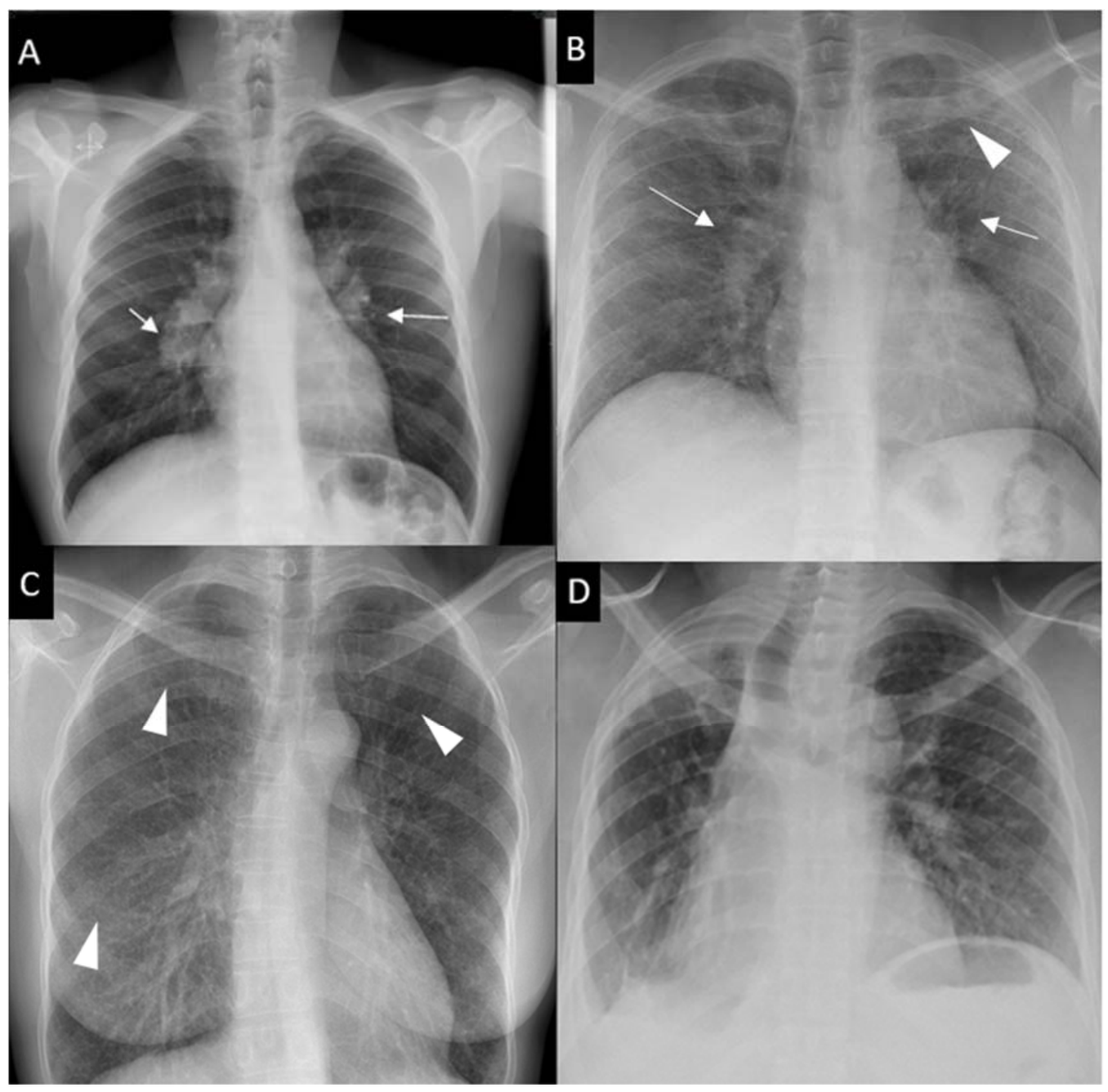

Figure 1. Chest $x$-ray (CXR) staging system. Stage 0-normal CXR (not shown); (A) Stage 1-bilateral hilar lymphadenopathy (white arrows); (B) Stage 2-bilateral hilar lymphadenopathy (white arrows) and pulmonary infiltrates in upper lobes (white arrowhead); (C) Stage 3-pulmonary infiltrates (white arrowhead) without bilateral hilar lymphadenopathy; (D) Stage 4-pulmonary fibrosis. 


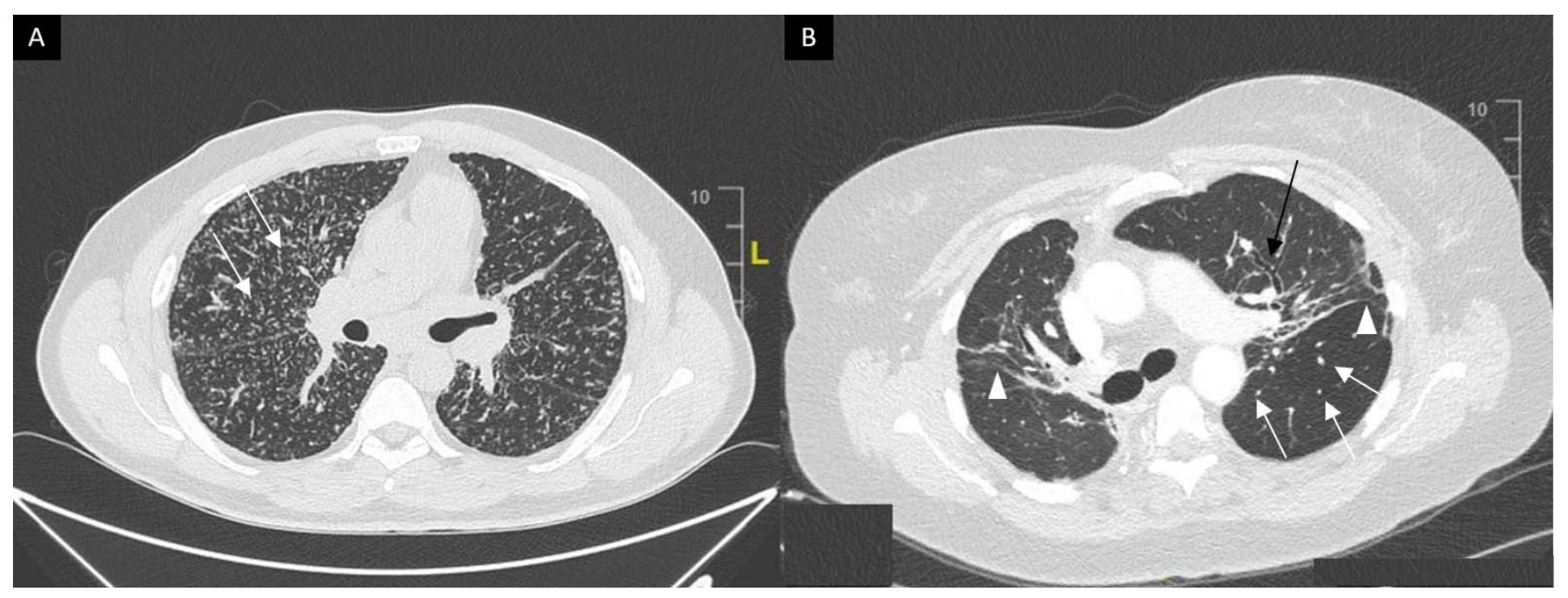

Figure 2. (A) Perilymphatic micronodules predominant in the right lung (white arrows). (B) Reticular opacities (white arrowheads), extensive traction bronchiectasis (black arrows) and perilymphatic nodules (white arrow) on lung windows. Findings consistent with sarcoidosis along with fibrosis.

As we discussed below, bronchoscopy with endobronchial and transbronchial lung biopsy as well as endobronchial ultrasound (EBUS) are cornerstones investigations for the histological diagnosis of sarcoidosis. Bronchoalveolar lavage (BAL) is a safe and minimally invasive procedure for the identification of the CD4+ alveolitis in sarcoidosis. The characteristic finding is a lymphocytic alveolitis in $80 \%$ of cases and $\mathrm{T}$ lymphocyte CD4/CD8 ratio over 3.5 in 50\% of cases [50]. However, BAL lymphocytosis is not specific for sarcoidosis and the importance of the CD4/CD8 ratio is controversial unless it is greater than 3.5, showing a specificity of 93 to $96 \%$. It is admitted that in inactive disease, the ratio is usually in the normal range. In most cases, BAL is not diagnostically decisive [36]. Eventually, the neutrophil count in BAL may increase in advanced sarcoidosis denoting the presence of pulmonary fibrosis and thus indicating an unfavorable prognosis [50]. High percentages of CD4 V2.3+ T cells $(>10.5 \%)$ are associated with a better prognosis [51]. CD103+CD4+ T cells count as well as CD103+CD4+/CD4 in BALF was also found to be relevant for sarcoidosis diagnosis. A cutoff point of 0.45 (where abnormal ratio is considered under this value) was found to be associated with acceptable diagnostic performances (sensitivity: $81 \%$; specificity: 78\%) even in patients with normal CD4/CD8 ratio in BAL fluid [52]. Heron et al. found that combining CD4/CD8 and CD103+CD4+/CD4 ratio can be an specific diagnostic tool (specificity: $92 \%$, positive predictive value: $93 \%$ ) when considering respective cutoffs of 3 and 0.2 , to differentiate patients with sarcoidosis from other interstitial lung diseases, even when CD4 alveolitis is missing [53].

The prevalence of pulmonary arterial hypertension (PAH) in sarcoidosis varies between studies depending on the characteristics of the study population and the methods used for the detection of PAH and its definition [54]. In studies of symptomatic patients or those waiting for lung transplantation, the prevalence of pre-capillary $\mathrm{PAH}$, defined by mean pulmonary artery pressure (mPAP) $>25 \mathrm{mmHg}$ with pulmonary arterial wedge pressure (PAWP) $<15 \mathrm{mmHg}$, is 5-74\% [54]. In sarcoidosis, complex pathophysiological interactions may occur between the pulmonary vascular system and the parenchymal, mediastinal and cardiovascular compartments. The diagnosis can only be confirmed with right heart catheterization [7]. Elevated pulmonary pressure can be attributed to the granulomatous involvement of the pulmonary vessels or be the consequence of parenchymal destruction or compressive mediastinal infiltration. Thus, in sarcoidosis, PAH is a complication with functional and prognostic consequences [54]. 


\subsection{Löfgren's Syndrome}

Löfgren's syndrome (LS), first described in 1952 by Swedish Professor of Medicine Sven Löfgren, is a clinically distinct phenotype of sarcoidosis. Patients typically experience an acute onset of the disease, usually with fever (53.4\%) and characteristic symptoms consisting in bilateral hilar lymphadenopathy, erythema nodosum (Figure 3) (57-100\%) and/or bilateral ankle arthritis or periarticular inflammation (81.2\%) [55]. LS occurs mostly in European Caucasians, especially in Sweden and in the Netherlands where LS patients constitute roughly a third of all sarcoidosis cases. It is less common in the United Kingdom and in the US, where only 0.9 and $0.7 \%$ of sarcoidosis patients present with LS, respectively, and is extremely rare in Asia. It usually occurs between the age of 25 to 40, with a second peak around the age of 40 to 60 and is more frequent in women (70\%) [56]. The different manifestations of LS differ according to sex. Erythema nodosum is found predominantly in women while arthropathy/arthritis is more common in men. In Löfgren's original cohort as well as in more recent studies, most patients (79-82.5\%) present with radiographic stage I, 14.6-23\% have stage II disease while no patient present with stage III/IV [55,56]. On average $2 \%$ of the patients have no radiographic abnormalities. Magnetic resonance imaging (MRI) of the joints or ultrasonography typically shows periarticular inflammation with subcutaneous and soft tissue edema accompanied by small amounts of joint and tenosynovial fluid without evidence of synovial thickening or synovitis $[57,58]$. LS patients herald a benign and self-remitting disease, which is especially true for individuals carrying the HLA-DRB $1 * 03$ allele. Chronic trend $>2$ years occurs in 8 to $22.6 \%$ of LS patients and is associated with older age, stage II at diagnosis and the need for treatment [55]. Apart from erythema nodosum, fever, articular involvement and extrapulmonary manifestations have been reported in only $12 \%$ of LS patients [16]. Among them, uveitis, parotitis, facial palsy, skin (except lupus pernio), liver or spleen involvement have been described as more frequently associated with LS.

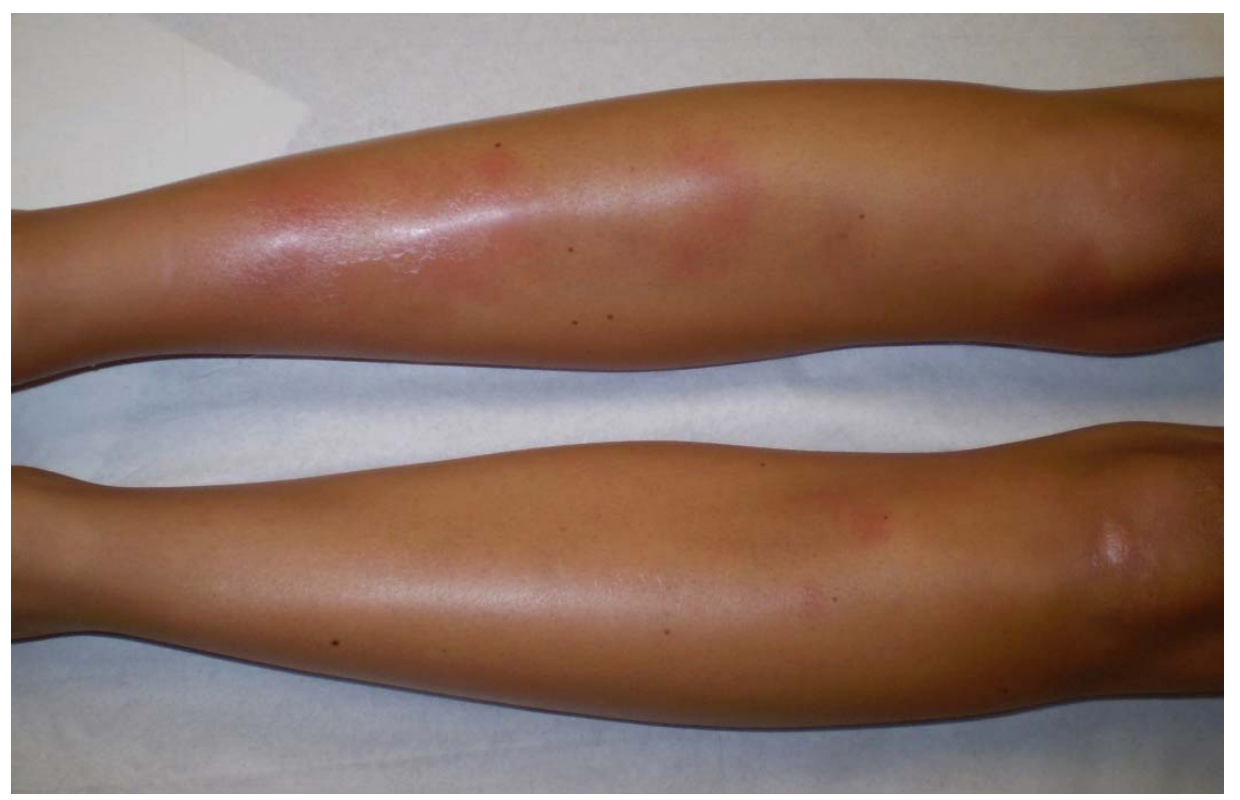

Figure 3. Erythema nodosum in a woman with Löfgren's syndrome.

\subsection{Musculoskeletal Manifestations}

Joint involvement, also known as sarcoid arthropathy, is observed in 6-35\% of patients and asymptomatic bone involvement occurs in 3-13\% of patients [59]. Other manifestations include sarcoid myopathy $(<3 \%)$ and hypercalcemia (around 6\%) [60].

Chronic sarcoid arthritis is less frequent (7\%) than LS and is also known to commonly affects the ankles [61]. It is characterized by persistent ( $>3$ months), symmetrical, oligo or polyarthritis of the medium and large joints in $20 \%$ of patients, with $40 \%$ arthralgia [62]. It is 
important to distinguish true synovitis from tenosynovitis, as the latter is more frequent [60]. Chronic forms have a less symmetrical joint and skin involvement distribution than LS, whereas ocular involvement is more frequent [61]. They are usually associated with parenchymal lung or extra articular sarcoidosis [60,63]. Polyarthritis only affecting the small joints of the hands is very rare and should be first considered as another systemic arthritis, such as rheumatoid arthritis, which may even coexist with sarcoidosis. Erosive changes and Jaccoud's-type arthropathy have been described in case-reports [64]. Erb et al. reported a $6 \%$ prevalence of spondyloarthritis in patients with sarcoidosis suggesting a possible association between the two conditions [65].

Bone sarcoidosis is observed in $0.5 \%$ to $30 \%$ of patients depending on the sensitivity of imaging procedures and is frequently associated with lupus pernio, uveitis and a chronic multisystemic course of the disease [60]. On the other hand, Sparks et al. reported only 20 cases (1.5\%) of osseous involvement detected in 2013 patients with sarcoidosis identified between 1994 and 2013 at Brigham and Women's Hospital in Boston, Massachusetts [66]. Bone lesions are asymptomatic in half cases. They are commonly located in the phalanges of the hands and feet and are usually bilateral. Dactylitis typically involves the bones and soft tissue with slight swelling, tenderness and limitations of the movement (Figure 4A). The skull, as well as long bones, ribs, pelvis and axial skeleton may also be affected. Radiographic investigations may revelate sclerotic (typically in the spine) and/or osteolytic lesions, cystic and punched out lesions and cortical abnormalities (Figure 4B). Vertebral sarcoidosis can affect lower thoracic and upper lumbar vertebrae and may mimic metastatic lesions. The use of more sensitive imaging procedures, such as MRI or nuclear imaging, reveals a higher rate of bone involvement than does radiography $[67,68]$. Using fluorine-18 fluorodeoxyglucose positron emission tomography/computed tomography $\left({ }^{18} \mathrm{~F}\right.$-FDG PET $\mathrm{CT}$ ), Demaria et al. have recently shown that bone sarcoidosis occurs in $14 \%$ of patients with sarcoidosis and affects multiple bones and mostly the axial skeleton (spine then pelvis, then sternum). Only patients with hand involvement had bony symptoms (pain and/or swelling) [69].

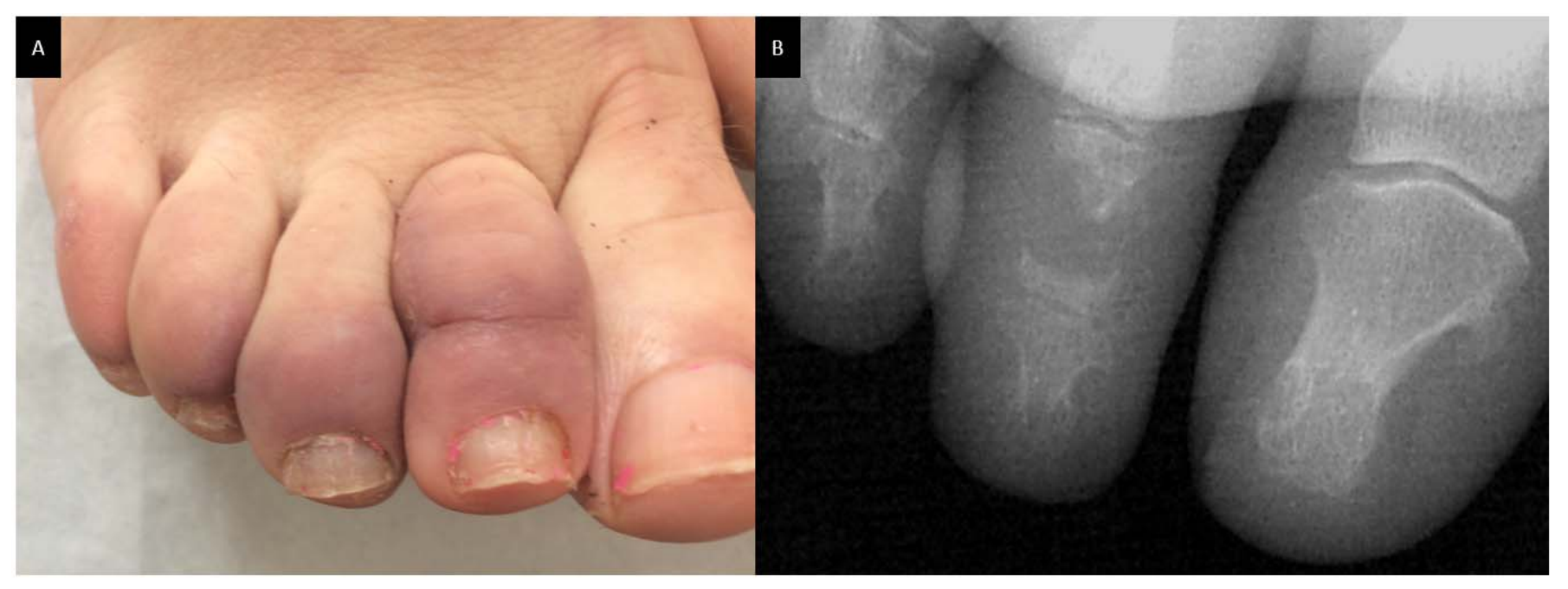

Figure 4. Dactylitis in a sarcoidosis patient; (A): skin on clinical examination; (B): X-ray on the same patient with punched out lesion of the second phalanx.

Asymptomatic granulomatous muscle involvement in sarcoidosis has already been reported, with a prevalence of $50-80 \%$ [70], whereas symptomatic muscle involvement is less common (1.4-2.3\%) [71,72]. Symptomatic involvement may include a palpable nodular type, which is infrequent; an acute myositis type, which is rare and seen more commonly in early sarcoidosis; and a chronic sarcoid myopathy type, which is more common, with a slower onset and occurs later in life [73]. Diagnostic difficulty may arise when the myopathy occurs in patients ongoing corticosteroid therapy, since corticosteroid-associated myopathy 
can present in a very similar manner to what is seen in sarcoid myopathy. As with bone sarcoidosis, ${ }^{18}$ F-FDG PET CT has emerged as a sensitive imaging technique for muscle involvement in sarcoidosis [74]. Most patients with acute sarcoid myopathy improve under systemic treatment, whereas chronic sarcoid myopathy is frequently associated with severe disability and rarely improves after corticosteroid treatment, immunosuppressive or anti-tumor necrosis factor (TNF)- $\alpha[75,76]$. In a recent study, including 23 patients with granulomatous myositis, Dieudonné et al. reported that almost half of the patients met the criteria for sporadic inclusion body myositis which was the only factor associated with unresponsiveness to treatment in patients with granulomatous myositis [77].

Depending on the studies and the study population, hypercalcemia affects $7-18 \%$ of patients with sarcoidosis [12,78-80]. In a case-control etiologic study of sarcoidosis named ACCESS, a multicenter prospective study with 736 enrolled patients, the incidence of sarcoidosis-associated hypercalcemia at onset was 3.7\%. The largest up-to-date study, a single-center retrospective study by Baughman et al. $(n=1606)$, reports that hypercalcemia appears in about $6 \%$ of sarcoidosis patients [81]. The majority of hypercalcemia in sarcoidosis are explained by the ectopic production of $1,25(\mathrm{OH})_{2} \mathrm{D}_{3}$ (calcitriol) by activated macrophages within granulomas. A more frequent sign of dysregulated calcium homeostasis in sarcoidosis is hypercalciuria which affects $20-40 \%$ of patients. As a consequence, nephrolithiasis is more frequent in sarcoidosis than in the general population as it occurs in $10-14 \%$ of patients during the course of the disease [82]. It is important to remember that sarcoidosis does not exclude other causes of hypercalcemia, starting with the most important: hyperparathyroidism and neoplasia, particularly lymphoma which can be associated with increased calcitriol production in granulomas [83].

\subsection{Skin}

According to studies, skin is the second or third most commonly affected organ in sarcoidosis, present in up to one-third of the patients [84]. Cutaneous sarcoidosis lesions are frequently the inaugural signs of the disease and sarcoidosis can remain an isolated dermatological condition in more than $30 \%$ of cases [85]. In patients with cutaneous and systemic sarcoidosis, skin findings rise before or at the time of diagnosis in $80 \%$ of patients [85]. Recognizing sarcoidosis cutaneous manifestations is of most importance as they are frequently the first sign of the disease and because skin is an easily accessible tissue for biopsy. There are "specific" and "non-specific" findings based on the presence or absence of characteristic sarcoidosic granulomas on histological examination.

There is a wide variety of sarcoidosis-specific skin lesions, some more common than others (Table 1). Skin manifestations are typically multiple erythematous macules, papules, plaques or subcutaneous nodules. They usually do not cause symptoms but they can be of aesthetic importance when localized to the face, as in the classical lupus pernio, which consists of indolent violaceous indurated plaques usually affecting the nose, cheeks and ear lobes. Specific cutaneous sarcoidosis may also occur in scar tissue, at traumatized sites and around embedded foreign bodies, such as in tattoos. Cutaneous sarcoidosis is often considered as a great mimicker. Psoriasiform, lichenoid, verrucous and angiolupoid are less frequently seen variants of papular or plaque sarcoidosis that can be confused with psoriasis, lichen planus, warts or lupus erythematosus, respectively. Some patterns of cutaneous involvement may be associated with specific extracutaneous manifestations of sarcoidosis, while other patterns may predict systemic disease severity and response to treatment. The clinical appearance may vary based on the morphological type of the lesion, its chronicity and the color of the surrounding skin (Figure 5). Erythema nodosum is the most common non-specific lesion, developing in up to $25 \%$ of cases [86]. Histological examination is not warranted since histological structure of erythema nodosum is not specific to sarcoidosis and never granulomatous. 
Table 1. Common and uncommon specific cutaneous sarcoidosis findings (From $[84,86])$.

\begin{tabular}{|c|c|c|}
\hline \multirow[t]{4}{*}{ Common } & $\begin{array}{l}\text { Papules and } \\
\text { papulonodules }\end{array}$ & $\begin{array}{l}\text { - Most common morphology of the specific cutaneous manifestations of sarcoidosis } \\
\text { - Description: numerous, firm, typically non-scaly, papular, usually smaller than } 1 \mathrm{~cm} \text { in size, } \\
\text { - } \quad \text { Color: flesh-colored, yellow-brown, red-brown, purple-brown or hypopigmented } \\
\text { - Location typically on the face, especially on the eyelids and nasolabial folds, but also on the } \\
\text { neck, trunk and extremities or within old scars } \\
\text { - Associated with a favorable prognosis }\end{array}$ \\
\hline & Plaques & $\begin{array}{l}\text { - Description: oval or annular in shape, often well-demarcated, typically firm and scaly } \\
\text { - } \quad \text { Color: red-brown to flesh-colored or purple-brown, sometimes yellow-brown } \\
\text { - } \quad \text { Location: back, buttocks, face and extensor surfaces of the extremities; can arise within scars } \\
\text { - } \quad \text { Associated with a chronic course }\end{array}$ \\
\hline & Lupus pernio & $\begin{array}{l}\text { - Can be disfiguring; tends to affect African Americans and women disproportionately; } \\
\text { associated with a chronic and refractory course, often requiring aggressive } \\
\text { systemic treatment } \\
\text { - Description: smooth shiny plaques, which may become scaly } \\
\text { - Color: brown to violaceous or erythematous } \\
\text { - Location: centrofacial, especially on the nose, cheeks, lips, forehead, ears. } \\
\text { - Sarcoidosic involvement of the upper respiratory tract, bones (most commonly fingers and } \\
\text { toes) and severe arthropathy are common. }\end{array}$ \\
\hline & $\begin{array}{l}\text { Subcutaneous } \\
\text { Nodules }\end{array}$ & $\begin{array}{l}\text { - Description: firm, mobile, round to oval subcutaneous nodules or in the deep dermis, often } \\
\text { with minimal surface changes } \\
\text { - } \quad \text { Color: erythematous, flesh-colored, violaceous, or hyperpigmented } \\
\text { - } \quad \text { Location: extremities, mainly upper extremities; trunk } \\
\text { - } \quad \text { May be associated with benign systemic disease (debated) }\end{array}$ \\
\hline \multirow[t]{6}{*}{ Uncommon } & Ichtyosiform & $\begin{array}{l}\text { - Description: fish scales, with adherent, polygonal, brown or white-gray scale } \\
\text { - } \quad \text { Location: lower extremities }\end{array}$ \\
\hline & $\begin{array}{l}\text { Atrophic and } \\
\text { ulcerative }\end{array}$ & - $\quad$ Depressed plaques, easily ulcerated \\
\hline & Mucosal & $\begin{array}{l}\text { - } \quad \text { Buccal mucosa, gingiva, hard palate, tongue, posterior pharynx and salivary glands } \\
\text { - } \quad \text { Papules, plaques, nodules and localized edema; papules or infiltrative thickening }\end{array}$ \\
\hline & Erythroderma & $\begin{array}{l}\text { Indurated, yellow-brown, red-brown, or purple-brown scaly plaques coalesce to involve } \\
\text { large areas of skin, often with fine superficial scale or mild exfoliative dermatitis }\end{array}$ \\
\hline & Alopecia & - Scalp: scarring or nonscarring alopecia \\
\hline & $\begin{array}{l}\text { Nail } \\
\text { sarcoidosis }\end{array}$ & $\begin{array}{l}\text { - Thinning, brittle and thickened nails, pitting, ridging, trachyonychia, hyperpigmentation, } \\
\text { clubbing or pseudo-clubbing, destruction of the nail plate and scarring (e.g., pterygium nail) }\end{array}$ \\
\hline
\end{tabular}

Erythema nodosum is mostly seen in LS and is associated with transient disease that does not require treatment. Other non-specific cutaneous findings of sarcoidosis include calcinosis cutis, clubbing and prurigo [84].

\subsection{Eyes}

The reported prevalence of ocular involvement ranges from $10 \%$ to $50 \%$, with a higher prevalence observed in African Americans than Caucasians and among women than men (female to male ratio of about 2:1). Ocular sarcoidosis may develop in the absence of any apparent systemic involvement or may be the main site of the disease without significant clinical disease elsewhere.

All ocular structures may be involved (Table 2), but uveitis is the most frequent form of ocular manifestation and may affect up to $20-30 \%$ of patients with sarcoidosis [87]. Apart from uveitis, lacrimal-gland enlargement (which can induce sicca syndrome) and conjunctiva involvement are the most frequent features while optic neuritis is challenging for the clinician because of its severity that often requires systemic treatment. 


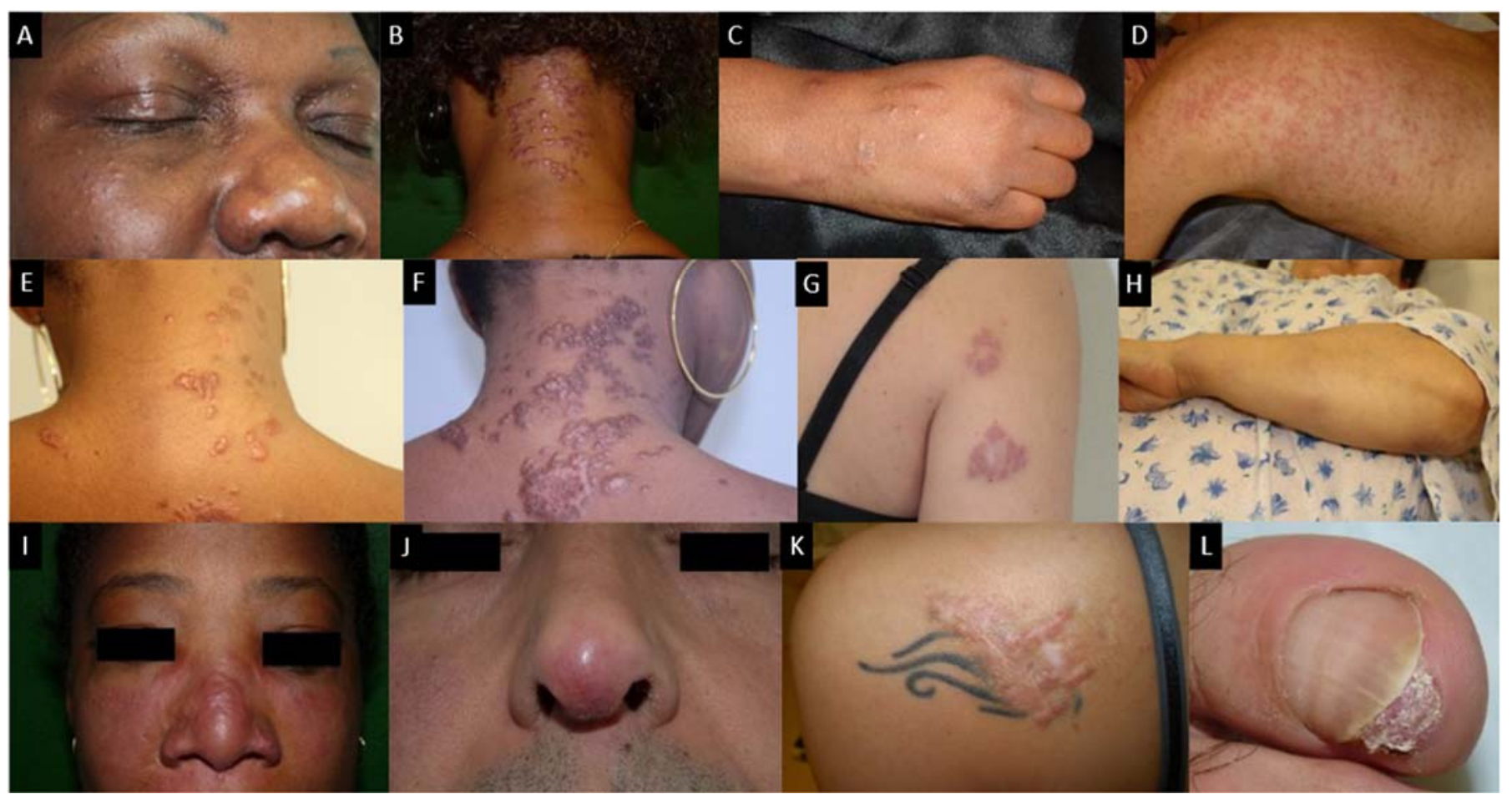

Figure 5. Skin sarcoidosis manifestations; (A-C): papular sarcoidosis, (D): diffuse maculopapular sarcoidosis; (E,F): Evolution of papular sarcoidosis into plaque sarcoidosis (same patient at a one-year interval); (G): annular plaque sarcoidosis; (H): subcutaneous sarcoidosis (Darier-Roussy type); (I): lupus pernio which has to be differentiated from (J): angiolupoid sarcoidosis (where telangiectasias are visible; $(\mathbf{K})$ : tatoo-sarcoidosis; $(\mathbf{L})$ : subungueal sarcoidosis.

Sarcoid uveitis is generally bilateral (75-90\%) with the same findings and clinical course in both eyes [88,89]. Anterior uveitis (defined as iritis and/or iridocyclitis) is the most common anatomical form of intraocular inflammation $(41-75 \%$ of sarcoid uveitis) $[88,90,91]$, followed by posterior, intermediate uveitis and panuveitis. Nevertheless, recent reports from tertiary centers identified panuveitis as the most commonly encountered subtype $[89,92]$. Anterior uveitis is usually chronic (defined as a relapse within 3 months after treatment discontinuation) [90], bilateral and granulomatous (Figure 6). Uveoparotid fever, also known Heerfordt(-Waldenström)'s syndrome is a highly specific subtype of sarcoidosis $[93,94]$. It is characterized by a combination of facial palsy, parotid gland enlargement, uveitis and is associated with low-grade fever [95]. Cases that manifest with all of the three symptoms are called "complete Heerfordt's syndrome" $(0.3 \%$ of sarcoidosis patients). If only two of the three characteristic symptoms are present, it is called" incomplete Heerfordt's syndrome" (1.3\%). Heerfordt's syndrome can be rarely associated with cranial nerve involvement, particularly affecting the trigeminal nerve [96] along with visceral involvement [97].

Sarcoid uveitis is associated with a favorable visual outcome, since most patients experience mild or no visual impairment $[98,99]$. However, 2.4 to $10 \%$ of patients with sarcoid uveitis develop severe visual impairment (defined as best-corrected visual acuity $<20 / 200$ in at least one eye) $[90,92,98,100]$ with cystoid macular edema being the main cause of visual loss $[98,101,102]$. Ocular inflammation related to sarcoidosis can have a smoldering course and patients can remain asymptomatic for a long time [103]. Therefore, ophthalmologic screening is recommended for all patients with newly diagnosed sarcoidosis, even in the absence of symptomatic ocular sarcoidosis. 


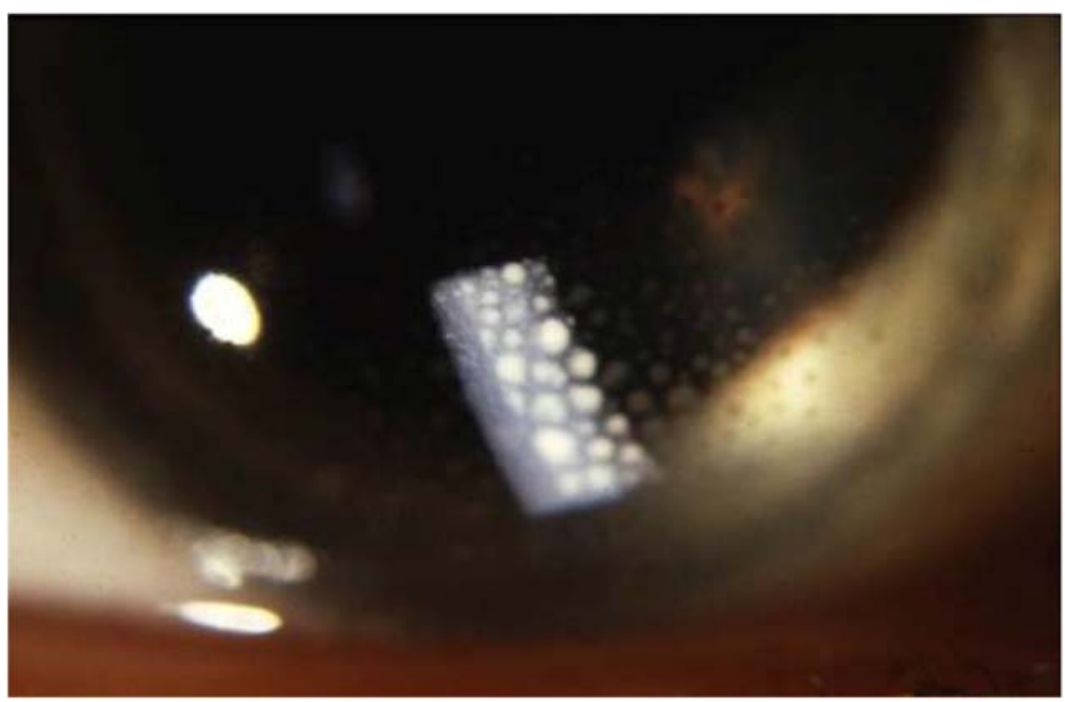

Figure 6. Large mutton-fat keratic precipitates (arrow) in sarcoidosis uveitis.

Table 2. Involvement of ocular structures and adnexa in sarcoidosis (except uveitis) (From [88,91,103-107]).

\begin{tabular}{|c|c|}
\hline Location & Description \\
\hline $\begin{array}{l}\text { Lacrimal glands and Lacrimal drainage } \\
\text { system }(10-69 \%)\end{array}$ & $\begin{array}{l}\text { Often asymptomatic. Keratoconjunctivitis sicca (15-31\%). Enlargement of the lacrimal } \\
\text { glands is less frequent; the diagnosis can be made on Lacrimal gland biopsy. }\end{array}$ \\
\hline \multirow{2}{*}{ Orbit } & $\begin{array}{l}\text { Women over 50. Diffuse orbital inflammation, usually unilateral, which can result in } \\
\text { ptosis, limitations of ocular movements and diplopia. }\end{array}$ \\
\hline & $\begin{array}{l}\text { Ocular nerve palsy can occur from sarcoid involvement of the 3rd, 4th and 6th } \\
\text { cranial nerves }\end{array}$ \\
\hline Eyelid & Granuloma \\
\hline Conjunctiva $(6-40 \%)$ & Paucisymptomatic. Granuloma, conjunctivitis \\
\hline Sclera $(<3 \%)$ & $\begin{array}{l}\text { Scleritis, episcleritis: diffuse inflammation, plaque or nodule; the diagnosis may be } \\
\text { made with biopsy of a scleral nodule }\end{array}$ \\
\hline Cornea & Interstitial keratitis (extremely rare). \\
\hline \multirow[b]{2}{*}{ Optic nerve $(1-5 \%)$} & Optic neuropathy $(++)$, granuloma, retrobulbar optic neuritis \\
\hline & $\begin{array}{l}\text { Predominantly Caucasian females. Frequently accompanied with uveitis and other } \\
\text { findings of neurosarcoidosis. Prognosis is not favorable and permanent impaired visual } \\
\text { acuity occurs in about one third of the patients. Sarcoidosis patients with opitc neuritis } \\
\text { often experience a chronic course of the disease and steroid-sparing alternatives are } \\
\text { commonly used. }\end{array}$ \\
\hline Other neuro-ophthalmic manifestations & Rare: Horner's syndrome, tonic pupil and optic-tract involvement \\
\hline
\end{tabular}

\subsection{Liver, Spleen and Gastrointestinal Involvement}

Autopsy series report hepatic involvement in up to $80 \%$ of cases [108]. However, asymptomatic elevation in liver-function tests in the context of known sarcoidosis is the most common presentation in approximately one-third of patients and occurs more frequently in African Americans than in Caucasians [109]. Of note, alkaline phosphatase seems to be more consistently elevated than aminotransferases in patients with hepatic sarcoidosis. Clinical manifestations include hepatomegaly, fatigue, right upper quadrant abdominal pain with pruritus (5-15\%), fever, jaundice and weight loss (less than 5\%) [110]. Portal hypertension has been reported in 3 to $20 \%$ of cases $[109,111]$ of sarcoid hepatitis and can be secondary to: (i) the obstruction of portal venous system due to large granulomas in the portal areas, causing a presinusoidal block; (ii) ischemia secondary to primary granulomatous secondary to granulomatous phlebitis of the portal and hepatic veins 
causing cirrhosis and focal fibrosis [112], or (iii) by arteriovenous shunts that increase portal blood flow [112]. Rare complications include Budd-Chiari syndrome, cholestatic liver disease mimicking primary biliary cirrhosis, primary sclerosing cholangitis, or obstructive jaundice $[113,114]$. CT scan and ultrasonography of the liver identify abnormalities in about half of the patients, with hypodense nodules being the most commonly observed (5-35\%), followed by hepatomegaly (8-18\%) [115-117]. MRI and ${ }^{18}$ F-FDG PET CT provide the best resolution and are the most sensitive modality for detecting liver nodules. The definitive diagnosis of hepatic sarcoidosis requires detection of non-caseating granuloma in the liver and exclusion of other diseases, such as alcoholic hepatitis, nonalcoholic liver fatty disease, infections and drug-induced liver injury. These granulomas are commonly focal and are found in the portal and periportal areas (although they can be found in all lobules) [118,119]. Common causes of granulomatous hepatitis include infections (e.g., Mycobacteria spp., Yersinia spp., Coxiella burnetii, Toxoplasma gondii, Bartonella henselae, Brucella spp., hepatitis $C$ virus), immunological disorders (e.g., primary biliary cirrhosis, Crohn's disease), environmental microparticles exposure (e.g., beryllium), neoplasms and drug reactions [120]. In the Western world, the two main causes of granulomatous hepatitis are primary biliary cirrhosis and sarcoidosis [121-123]. Inflammation of the liver can persist and cirrhosis can develop in a minority of patients (3-6\%) [124].

Splenic involvement is most often detected by imaging rather than by symptoms or laboratory abnormalities and has been reported with a similar frequency as hepatic involvement. It may present with constitutional symptoms and marked splenomegaly in up to $6 \%$ of cases $[116,125]$. CT show spleen enlargement or splenic nodules which can be observed in up to $15 \%$ of abdominal CTs, as single or multiple hypodense lesions larger than $1 \mathrm{~cm}$, with an irregular shape and a confluence tendency. Punctate, hyperdense calcifications have been found in up to $16 \%$ of the patients and also more clearly calcified lesions have been reported [126,127]. A recent study showed that diffuse splenic involvement was associated with an extensive extrapulmonary course and diffuse endobronchial disease and appears to be a risk factor for persistent chronic sarcoidosis [128].

An enlargement of the abdominal lymph nodes is present in about $30 \%$ of patients and is mainly located in the hepatic hilum and at the para-aortic and celiac sites, around iliac vessels or in the mesentery. The lesions usually appear hypodense with size ranges from 1 to $2 \mathrm{~cm}$. Lymph nodes greater than $2 \mathrm{~cm}$ are observed in up to $10 \%$ of patients, which raise the problem of differential diagnosis with malignant lesions such as lymphoma $[126,129,130]$.

Gastrointestinal tract involvement is extremely rare, described in 0.1 to $1.6 \%$ of cases [131]. Gastric or intestinal sarcoidosis presents with abdominal pain, weight loss, nausea, vomiting, protein-loss enteropathy and signs of gastrointestinal obstruction or bleeding. These findings are also seen in Crohn's disease [132,133]. On endoscopy, macroscopic lesions are observed in the esophagus $(9 \%)$, stomach $(78 \%)$, duodenum $(9 \%)$, colon $(25 \%)$ and rectum (19\%). As compared with Crohn's disease, digestive tract sarcoidosis is associated with Afro-Caribbean origin and the absence of ileal or colonic macroscopic lesions [131].

\subsection{Cardiac Sarcoidosis}

Cardiac involvement affects approximately 3 to $39 \%$ of patients with systemic sarcoidosis [134-140]. However, autopsy series of patients with systemic sarcoidosis reported cardiac granulomas in a higher proportion (up to $46.9 \%$ of cases) [141,142]. There is a predilection for the left ventricular wall, the interventricular septum and the conducting system but any part of the heart can be affected [143]. Patients with cardiac sarcoidosis (CS) are mostly asymptomatic, but may present with chest pain, palpitations, dyspnea, congestive heart failure, pericardial effusion or syncope/presyncope due to arrhythmias. The most common abnormality is atrioventricular block (45\%) [144]. For this reason, any conduction defect on electrocardiogram (bundle branch block, prolonged PR interval) or other nonspecific changes should prompt further cardiological investigations. Pathological $\mathrm{Q}$ waves (pseudo-infarct pattern), ST segment and T wave changes and rarely epsilon 
waves can occur [138]. Current ATS guidelines recommend that electrocardiogram should not be performed every year in any patient with known sarcoidosis since clinically silent CS usually follows a benign course $[27,145]$.

Other classical manifestations include arrhythmia (atrial or ventricular (35.6\%) [146] and cardiomyopathy leading to heart failure (10-20\% of patients). Less commonly, CS may manifest as pericardial, valvular or coronary heart disease. Transthoracic echocardiography (TTE) sensitivity in CS is around 25\% [139,140]. Interventricular thinning (particularly basal interventricular thinning) is the most typical feature of CS and has been shown to be highly specific for diagnosis. Other features include increased myocardial wall thickness, ventricular aneurysms, left ventricular and/or right ventricular diastolic and systolic dysfunction and isolated wall movements abnormalities [147].

TTE is a good screening tool for diagnosis when facing respiratory or cardiac symptoms in sarcoidosis, making it possible to rule out several differential diagnoses, such as pulmonary hypertension, valvular disease, or ischemic heart disease. Of note, a normal TTE does not exclude CS.

Cardiac MRI (CMRI) is the cornerstone for the diagnostic work-up of CS given its sensitivity and specificity (both over 90\%), by identifying areas of myocardial damage including edema and scarring, primarily through late gadolinium enhancement (LGE) $[138,140,148]$. LGE is typically multifocal and patchy and is usually seen in the epicardium and midmyocardium. The prognostic value of LGE on CMRI is equally important and allows risk stratification in cardiac sarcoidosis, since LGE is associated with death and ventricular tachycardia as well as the size of the granulomatous infiltrate which is associated with a poor prognosis [140,149-152].

${ }^{18}$ F-FDG PET CT has a fair diagnostic accuracy for CS, with a meta-analysis reporting a pool sensitivity of $89 \%$ and specificity of $78 \%$ [153]. Considering such evidence, the latest guidelines have positioned CMRI above TTE and ${ }^{18} \mathrm{~F}$-FDG-PET/CT for the confirmation of suspected CS in patients with extracardiac sarcoidosis [27]. Serial PET imaging is useful in monitoring disease activity and response to immunosuppressive therapy [154].

Endomyocardial biopsy has a low sensitivity $(\sim 30 \%)$ given the patchy nature of cardiac sarcoidosis and is an invasive procedure [155].

\subsection{Neurosarcoidosis}

Neurological involvement in sarcoidosis is relatively uncommon, with a reported prevalence of 3 to $10 \%$ [156]. Isolated neurosarcoidosis is very rare (1-17\%), with 84 to $94 \%$ of cases experiencing coexisting systemic manifestations of sarcoidosis, especially in the lungs and intrathoracic lymph nodes [157]. In approximately half of the cases of patients with neurosarcoidosis, neurological symptoms are the first manifestation that leads to the identification of the disease [158].

Every part of the nervous system can be affected and multiple parts can be affected at the same time, some more commonly than others (Table 3) $[159,160]$. The most frequently affected sites are the cranial nerves (55\%), the meninges (12-40\%), the brain parenchyma $(20-45 \%)$ and the spinal cord $(18-26.5 \%)$ [161]. The involvement of the pituitary gland $(13.7 \%)$, peripheral nerves $(10.3$ to $17 \%)$ or stroke $(2.6 \%)$ are less common [156,162]. All cranial nerves can be affected in neurosarcoidosis, with cranial nerves II, VII and VIII being the most commonly involved. On imaging studies, leptomeningeal abnormalities are three times more frequently detected than pachymeningeal disease [158].

Cerebrospinal fluid (CSF) angiotensin converting enzyme (ACE) had been proposed as a diagnostic tool with a relatively good specificity (67.3-95\%) [163]. However, its sensitivity is low, ranging from 0 to $66.7 \%[156,164]$. The CD4/CD8 ratio in CSF is higher in neurosarcoidosis than in multiple sclerosis and other neurological inflammatory disorders and may be helpful for the differential diagnosis [165]. Hypoglycorachia (up to 14\%) and oligoclonal bands (up to $42 \%$ ) are also biological features associated with neurosarcoidosis [156]. The differential diagnosis of intraparenchymal lesions is quite broad, including life-threatening conditions such as infections (e.g., tuberculosis), tumor (e.g., lymphoma) 
or other CNS inflammatory disorders (e.g., multiple sclerosis or neuromyelitis optica). Therefore, histopathological confirmation is generally necessary, although biopsy of those lesions is often technically challenging, with a relatively high rate of false-negative results (up to $40 \%$ in the Stern et al.'s study) [166].

Spinal cord sarcoidosis (SCS) occurs in less than 1\% of all patients [167-169]. In comparison with other myelopathies, neurologic pain seems to be more frequent and may be considered as an alarm for early diagnosis of SCS [170]. Sarcoidosis associated myelitis is usually extensive (more than three vertebral levels) with a subacute/progressive onset compared with other myelopathies (vascular, inflammatory, or infectious myelopathies) (Figure 7). A distinct MRI phenotype, with enhancement in subpial and/or meningeal areas, also called "trident sign", is seen in sarcoidosis-associated myelopathy and can help the diagnosis [171].

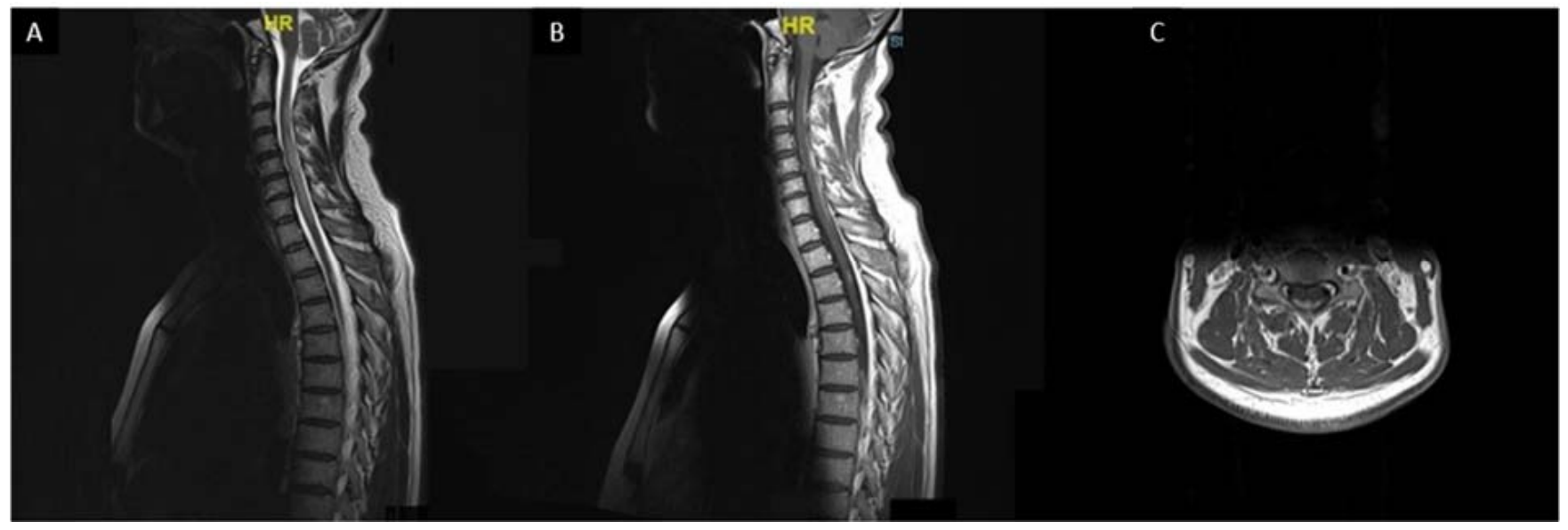

Figure 7. Sarcoidosis associated myelitis: (A): T2-weighted sagittal MRI slice showing longitudinally extensive T2 hyperintensity of the cervical and upper thoracic spinal cord associated with a focal T2 hyperintensity at T3 vertebra level; (B,C): T1-weighted post gadolinium sagittal (B) and axial (C) MRI images showing posterior subpial enhancement of the lesions.

Hypothalamo-pituitary (HP) involvement is a rare manifestation of sarcoidosis, representing less than $1 \%$ of all intrasellar lesions [172]. Patients with HP sarcoidosis have significantly more frequent sinonasal and neurological involvement and more frequently require systemic treatment [173].

Peripheral neuropathy is rare in sarcoidosis. Nerve biopsy is often required to confirm the diagnosis. Small fiber neuropathy (SFN) is increasingly recognized as another manifestation of neurosarcoidosis and seems to be quite common with a reported prevalence of up to $10 \%$ of all patients with sarcoidosis in a retrospective study [174]. SFN symptoms can be disabling and severely impact quality of life [19]. Symptoms associated with SFN include pain and autonomic disorders such as dry eyes or mouth, orthostatic hypotension and urinary dysfunction [175]. Its detection is essential as sarcoidosis treatments may improve SFN-associated symptoms [176]. Classic electrophysiological tests usually fail to assess small fibers damages and indirect testing such as sudomotor testing or more specific investigations such as intraepidermal nerve fiber density in skin biopsy. Hoitsma et al. provided a diagnostic tool to detect small fiber neuropathy in sarcoidosis patients consisting of a brief and reproductible questionnaire [177]. 
Table 3. Common and uncommon neurological sarcoidosis findings and their evolution. From [156,158,161,164,169,173,178].

\begin{tabular}{|c|c|c|}
\hline \multirow[t]{3}{*}{ Common } & $\begin{array}{l}\text { Cranial } \\
\text { nerves }\end{array}$ & $\begin{array}{l}\text { - VII }(24 \%), \text { II }(21 \%) \text { (see Table } 2), \mathrm{V}(12 \%), \mathrm{VIII}(3-10 \%) \text {, oculomotor nerves, }(2-6 \%), \text { XI, XII }(1 \%) \text {. } \\
\text { - Underlying mechanisms could be either epineural/perineural granulomatous inflammation of the nerve } \\
\text { itself or granulomatous inflammation of the leptomeningeal compartment compressing the cranial nerves. } \\
\text { Facial palsy is usually unilateral, but both sides can be affected at the same time in up to } 30 \% \text { [161]. } \\
\text { Prognosis is usually good, with complete recovery in about } 90 \% \text { of patients under corticosteroids. } \\
\text { - Hearing loss is bilateral and asymmetrical in } 75 \% \text { of patients [179]. Half of the patients have abnormal } \\
\text { vestibular testing and most of them have additional features of neurosarcoidosis }(81 \%) \text {. Recovery occurs in } \\
\text { most patients }(70 \%) \text {. }\end{array}$ \\
\hline & Meningeal & $\begin{array}{l}\text { - Clinical symptoms of meningeal irritation are seen in only } 10 \% \text { to } 20 \% \text { of patients with neurosarcoidosis. } \\
\text { - Many patterns of meningeal involvement have been described, but there is a tendency to basilar meninges } \\
\text { involvement [164]. } \\
\text { Leptomeningeal disease is a more severe disorder, with a risk of hydrocephalus and tissue destruction. } \\
\text { Hydrocephalus is due to the obstruction of the ventricles by an inflammatory or granulomatous mass or } \\
\text { infiltration of the meningeal spaces. } \\
\text { CSF usually reveals mild monocyte pleocytosis }(64 \%) \text { and a protein elevation }>1 \mathrm{~g} / \mathrm{L}(70 \%) \text {. Low glucose } \\
\text { level (one-fifth of cases) and oligoclonal bands (30-42\% of cases) are correlated with disability. }\end{array}$ \\
\hline & $\begin{array}{l}\text { Brain } \\
\text { parenchyma }\end{array}$ & $\begin{array}{l}\text { - Intraparenchymal granulomatous lesions could be either a solitary mass or multiple nodules and may cause } \\
\text { focal neurologic deficits, seizures, or increased intracranial pressure. } \\
\text { Multiple non-enhancing white matter lesions are the most common imaging findings in sarcoidosis patients } \\
\text { on MRI. These lesions are hyperintense on T2-weighted sequences and may be indistinguishable from those } \\
\text { of multiple sclerosis. }\end{array}$ \\
\hline
\end{tabular}

Uncommon Spinal cord - Most patients present with insidious, progressive, but non-specific sensory disorders, sphincter dysfunction and weakness over months before diagnosis [169].

- $\quad$ Cervical $(59 \%)>$ thoracic $(29 \%)>$ conus $(12 \%)$ involvement.

- $\quad$ On MRI, spinal cord sarcoidosis appears as heterogeneous patchy intramedullary lesions, a longitudinally extensive transverse myelitis with cord swelling and spinal cord atrophy in the late stages.

- $80 \%$ of patients will develop neurologic sequelae and $40 \%$ to $61 \%$ with a moderate to severe handicap.

Pituitary - Hypogonadism is the most frequent endocrine disorder followed by TSH deficiency, diabetes insipidus and hyperprolactinemia [173].

- $\quad$ MRI reveals infundibulum involvement (36.3\%), pituitary stalk thickness (52\%) and involvement of the pituitary gland (64\%).

- $\quad$ MRI abnormalities can improve or disappear under corticosteroid treatment, but most endocrine defects are irreversible and require long-term substitutive opotherapy.

Peripheral - The most common form is chronic axonal sensory and/or motor neuropathy polyneuropathy [180]. neuropathy - Other forms include multiplex mononeuropathy, radiculopathy, brachial/lumbar plexitis, subacute demyelinating polyneuropathy mimicking Guillain-Barré syndrome, chronic demyelinating inflammatory neuropathy

- Epineural and perineural granulomas, as well as granulomatous vasculitis can cause ischemic axonal degeneration and demyelination resulting from local pressure.

- $\quad$ The prognosis is good for most patients after treatment, especially when there is a less severe presentation and a recent onset of symptoms [181]

- Small-fiber neuropathy: patients usually present with pain, burning sensation and paresthesia. These symptoms can be migratory and fluctuant. Dysautonomia causing orthostatic hypotension, palpitations, hyperhidrosis, gastrointestinal dysmotility, or bowel/bladder dysfunction is also observed in approximately half of patients. The diagnosis of small fiber neuropathy requires skin biopsy showing decreased intraepidermal nerve fiber density of lower than $5 \%$ of the population reference mean or quantitative sudomotor axonal reflex testing showing reduced sweat output [174].

Stroke - Strokes which are thought to be related to sarcoidosis are ischemic (69\%) or hemorrhagic (31\%) [182]

- The main pathophysiological mechanism seems to be a granulomatous invasion of the vessels rather than cerebral vasculitis.

- $\quad$ Cardioembolic events (e.g., atrial fibrillation associated to cardiac sarcoidosis) and atherosclerotic lesions have to be excluded

Abbreviations: MRI: Magnetic Resonance Imaging.

\subsection{Kidney Involvement}

Granulomatous interstitial nephritis is the classic renal pattern of sarcoidosis, reported in up to $13 \%$ of patients in autopsy studies [183]. However, clinically evident interstitial nephritis is quite rare and is observed in 0.7 to $4.3 \%$ in clinical studies, suggesting a nonaggressive course of renal disease $[12,15,184,185]$. Except the patients diagnosed on autopsy, impairment of renal function with or without abnormal urinalysis results (microscopic hematuria $(21.7 \%)$, aseptic leukocyturia $(28.7 \%)$ and moderate proteinuria $(66 \%))$ is the most common presentation [183]. Most of them have experienced extrarenal sarcoidosis, with a higher frequency of hypercalcemia $(32 \%)$ and fever $(17 \%)$ at presentation $[183,186]$. A total of $19 \%$ to $21.3 \%$ of renal biopsies reveal only signs of interstitial nephritis without 
granuloma, which may reflect the inflammatory process or biopsy sampling error $[183,186]$. However, noncaseating granulomatous interstitial nephritis is not pathognomonic of renal sarcoidosis. Several diseases, such as tuberculosis, Mycobacterium avium infection, leprosy, fungal infections, foreign body reactions, inflammatory diseases (tubulointerstitial nephritis with uveitis syndrome, granulomatosis with polyangiitis and Crohn's disease), crystal nephropathies and drug allergies can give rise to the same histopathologic picture [187-189].

Other renal diseases can be associated with sarcoidosis like nephrocalcinosis, nephrolithiasis secondary to hypercalcemia and hypercalciuria (see musculoskeletal manifestations section). Clinical manifestations are similar to those of nephrocalcinosis and nephrolithiasis from other causes [190].

Finally, glomerular diseases (membranous nephropathy, focal segmental sclerosis, mesangial proliferative glomerulonephritis, IgA nephropathy and extra capillary/crescentic glomerulonephritis) and isolated tubular dysfunction have been more rarely be reported [191].

\subsection{Otolaryngological Involvement}

Approximately $10-15 \%$ of the patients have symptomatic specific otolaryngological involvement of the larynx (0.5-1.4\%), the major salivary glands, including Heerfordt's and Mikulicz's syndromes (5-10\%) and the nose and paranasal sinuses (1-4\%) [192,193]. While major salivary gland involvement most frequently follows a benign course, sinonasal and laryngeal sarcoidosis are usually severe, associated with other serious manifestations, with a particularly longstanding course and represent a therapeutic challenge. Patients with sinonasal disease have non-specific symptoms including: nasal obstruction (90\%), rhinorrhea $(70 \%)$, anosmia $(70 \%)$, crusting rhinitis $(55 \%)$, epistaxis $(30 \%)$ and facial pain (20\%) [193]. Based on the clinical presentation, Lawson et al. have classified sinonasal sarcoidosis into four subgroups: atrophic, hypertrophic, destructive and associated with nasal enlargement [194]. Laryngeal sarcoidosis usually involves the supraglottis (epiglottis, then arytenoids) and does not affect the vocal cords [195]. The most common symptoms are hoarseness (three-quarters of patients), inspiratory dyspnea (38-90\%) and dysphagia (38-46.7\%) [196,197]. It is often associated with other loco-regional localizations as lupus pernio and sinonasal involvement [196].

\section{Clinical Phenotypes}

In recent years, three studies have investigated the heterogeneity of sarcoidosis in order to identify clinical phenotypes with similar combinations of traits. In 2018, the GenPhenReSa project, involving 2163 Caucasian patients recruited from pulmonology departments, proposed five clinical clusters: (1) abdominal organ involvement, (2) ocularcardiac-cutaneous-central nervous system involvement, (3) musculoskeletal-cutaneous involvement, (4) pulmonary and intrathoracic lymph node involvement and (5) extrapulmonary involvement [135].

Using cluster analysis in a cohort of 694 patients seen at their university hospital, Rubio-Rivas and Corbella identified six discrete phenotype subgroups: C1 (pure LS with bilateral hilar lymphadenopathy (BHL) and erythema nodosum [EN]), C2 (febrile LS), C3 (non-febrile LS with periarticular ankle inflammation), C4 (exclusive pulmonary sarcoidosis), C5 (pulmonary sarcoidosis and "abdominal" involvement) and C6 (organ involvement different from the lungs, including: skin lesions, peripheral lymph nodes and neurological and ocular involvement). Contrary to the first three subsets, most patients with C4-6 phenotypes were treated with immunosuppressive therapy and evolved to chronicity to a greater extent. More recently, the EpiSarc study analyzed 1237 patients from 11 French hospital centers [198]. The hierarchical cluster analysis identified five distinct phenotypes according to organ involvement, disease type and symptoms: $(1)(n=180) L S ;(2)(n=137)$ eye, neurological, digestive and kidney involvement; $(3)(n=630)$ pulmonary involvement with fibrosis and heart involvement; ( 4$)(n=41)$ lupus pernio and a high percentage of severe involvement; and (5) $(n=249)$ hepatosplenic, peripheral lymph node and bone involvement. 
Phenotype 1 was associated with European origin, female sex and with non-manual work; phenotype 2 with European origin; and phenotypes 3 and 5 with being non-European. The proportion of labor workers was significantly lower in phenotype 5 than in the other phenotypes. Altogether, these results suggest that these distinct phenotypes are sequelae of different etiological agents causing sarcoidosis that are either inhaled, ingested or passed through the skin, eyes and/or the blood-brain barrier [199]. In addition, different genetic risk profiles may predispose to these different phenotypes. Several studies are ongoing to associate clinical phenotypes with biological pathways and specific genotypes [135].

\section{Diagnosis}

The diagnosis of sarcoidosis is based on three major criteria: consistent and adequate clinical presentation; demonstration of the presence of non-caseating granulomas in one or more tissue samples; and the exclusion of other causes of granulomatous disorders [27]. In order to establish uniform standards for the probability of organ involvement in sarcoidosis, consensus criteria were originally established in 1999 [3], then updated in 2014 [200] by the World Association of Sarcoidosis and Other Granulomatous Disorders (WASOG), according to a Delphi study. Clinical manifestations were assessed as either:

- highly probable: likelihood of sarcoidosis causing this manifestation of at least $90 \%$ (e.g., uveitis, bilateral hilar adenopathy, perilymphatic nodules on chest CT);

- probable: likelihood of sarcoidosis of 50-90\% (e.g., seventh cranial nerve paralysis, lachrymal gland swelling, upper lobe or diffuse infiltrates);

- Possible: likelihood of sarcoidosis of less than $50 \%$ (e.g., arthralgias, localized infiltrate on CXR) [200].

In 2018, using the WASOG organ involvement criteria, Bickett et al. proposed a Sarcoidosis Diagnostic Score which might accurately differentiate sarcoidosis from other granulomatous diseases [201]. An update of the international guidelines for the diagnosis and management of sarcoidosis published in 1999, was released in April, 2020 [27]. These guidelines have been developed according to the GRADE (Grading of Recommendations Assessment, Development and Evaluation) based on a systematic review of the literature and, where appropriate, meta-analysis, in order to summarize the best available evidence. The three recommendations about diagnosis were related to pathomorphological examination of the lymph nodes.

While many sarcoidosis cases constitute a diagnostic dilemma, certain clinical features are considered to be highly specific of the disease. These include LS, lupus pernio and Heerfordt's syndrome (See above). In these settings, the American Thoracic Society (ATS) experts suggest that lymph nodes should not be collected (conditional recommendation, very low quality evidence).

A total of 16 studies were conducted in 556 asymptomatic patients with suspected radiographic stage 1 sarcoidosis and showed that sarcoidosis was confirmed in $85 \%$ of patients, while an alternative diagnosis was made in $1.9 \%$ (i.e., tuberculosis in $38 \%$ of cases and lymphoma in $25 \%$ of cases). Sampling was non-diagnostic in $11 \%$ of cases. Based on these data, experts make no recommendation for or against obtaining a lymph node sample in asymptomatic patients whose changes in the radiological image indicating bilateral hilar lymphadenopathy. The need for closer clinical examination is emphasized in patients whose biopsy was postponed. The third recommendation, for patients with suspected sarcoidosis along with hilar/mediastinal lymphadenopathy, is to perform Endobronchial Ultrasound (EBUS)-guided lymph node sampling, rather than mediastinoscopy (conditional recommendation, very low quality). Agrawal et al. recently performed a systematic review and meta-analysis which yielded, for sarcoidosis, a pooled overall diagnostic yield of $93 \%$ for EBUS-intranodal forceps biopsy vs. 58\% for EBUS-transbronchial needle biopsy $(p<0.00001)$ [202]. Figure 8 provides an algorithm based on recent ATS guidelines for the diagnosis of sarcoidosis and that incorporates the value of minor salivary gland biopsy (MSGB) and ${ }^{18}$ F-FDG PET in sarcoidosis diagnosis $[27,36,99]$. Two studies in uveitis pa- 
tients showed that granulomas were only found on MSGBs in patients with elevated ACE or with a compatible chest CT [203,204].
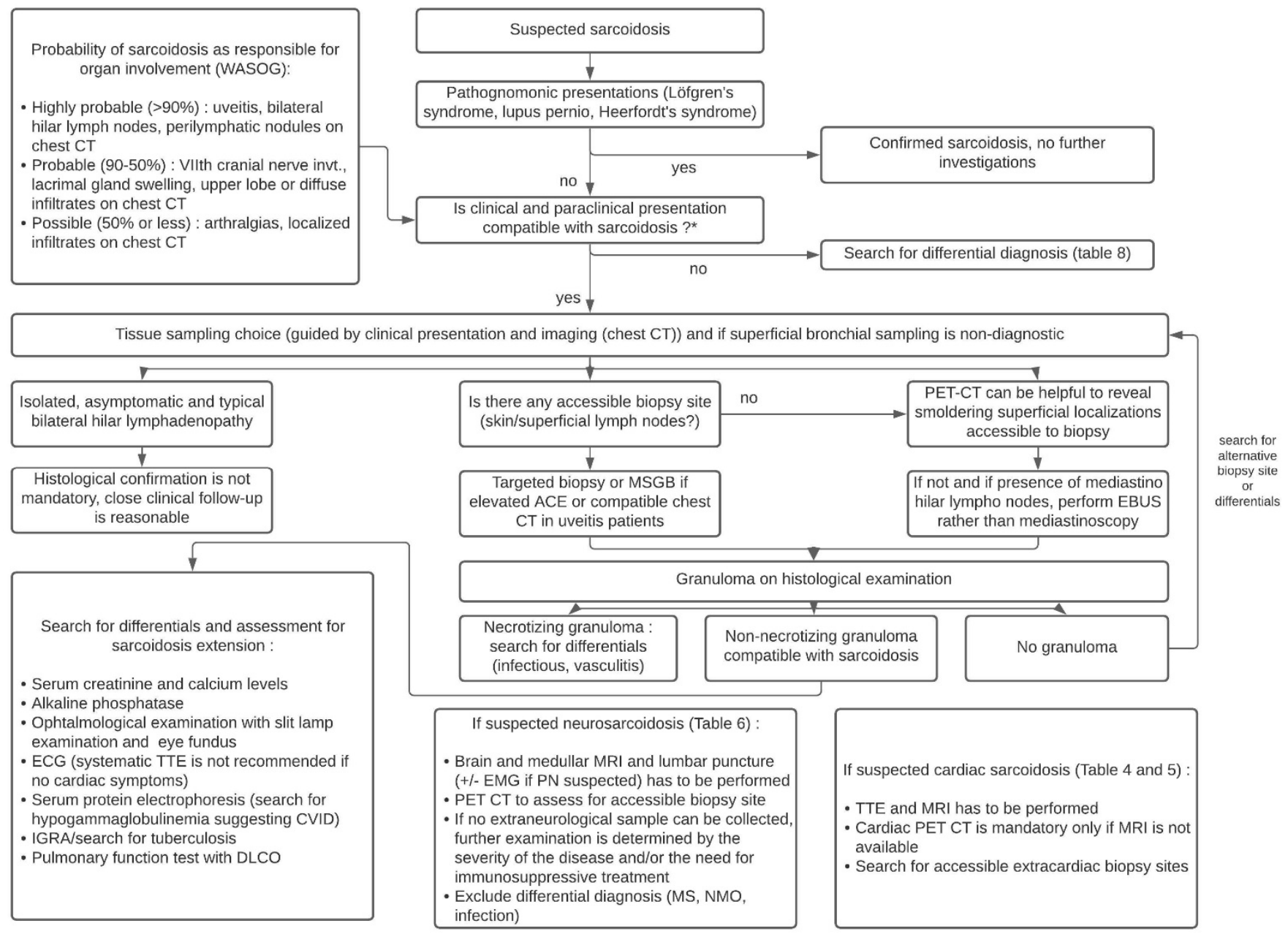

Figure 8. Diagnostic algorithm of sarcoidosis according to the ATS guidelines. Abbreviations: ACE: angiotensin converting enzyme; CT: computed tomography; CVID: common variable immunodeficiency; EBUS: endobronchial ultrasonography; EMG: electromyogram; KCO: organic carbon absorption coefficient; MRI: magnetic resonance imaging; MS: multiple sclerosis; MSGB: minor salivary glands biopsy; PET: positron emission tomography; PN: polyneuropathy; NMO: neuromyelitis optica; TTE: transthoracic echocardiography; WASOG: World Association of Sarcoidosis and other Granulomatous disorders.

In case of poorly accessible organ localization without superficial nor thoracic manifestation (e.g., cardiac or neurosarcoidosis) ${ }^{18}$ F-FDG PET may show a suggestive sarcoid-like uptake pattern with hypermetabolic mediastinal and hilar lymph nodes, whether or not combined with lung parenchymal active disease which supports the likelihood of sarcoidosis and orientates a mediastinoscopy [205]. ${ }^{18}$ F-FDG PET may sometimes reveal smoldering superficial localizations, for example, cervical lymph nodes which are easily accessible to biopsy (Figure 9) [206]. The value of EBUS-guided lymph node sampling in patients with hypermetabolic lymph nodes on ${ }^{18}$ F-FDG PET remains to be studied.

\subsection{Specific Diagnostic Criteria in Cardiac, Neuro and Ocular Sarcoidosis}

\subsubsection{Cardiac Sarcoidosis}

Due to the current limitations of endomyocardial biopsy as a reference standard, physicians mainly rely on advanced cardiac imaging, multidisciplinary evaluation and specific diagnostic criteria to diagnose cardiac sarcoidosis. The revised Japanese Ministry of Health and Welfare diagnostic criteria (Table 4) and the Heart Rhythm Society Expert Statement 
Criteria (Table 5) are currently the two main well-established diagnostic criteria guidelines for cardiac sarcoidosis [138,148]. Nevertheless, these two sets of diagnostic criteria were mainly based on expert consensus and have not yet been validated by prospective data or clinical trials [207].

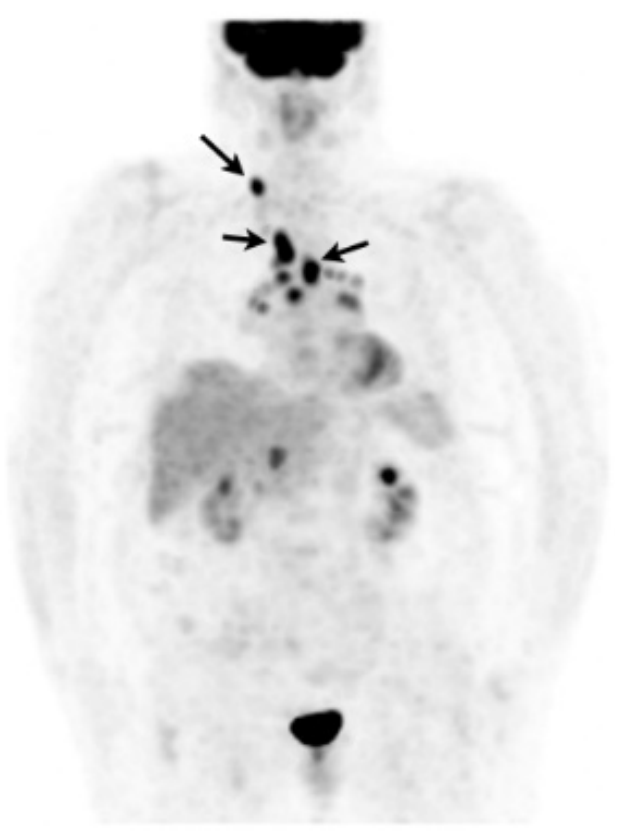

Figure 9. Caucasian woman (78 years old) suffering from bilateral unexplained panuveitis. Whole body ${ }^{18}$ F-FDG PET (maximum intensity projection anterior view) demonstrated significant bilateral hilar, mediastinal and right supraclavicular lymph nodes uptakes (black arrows) while there was no node enlargement on chest CT. A subsequent supraclavicular node dissection revealed noncaseating epithelioid granulomas consistent with sarcoidosis. Special staining and culture for mycobacteria were negative.

Table 4. Japanese Ministry of Health and Welfare criteria for diagnosing cardiac sarcoidosis [208].

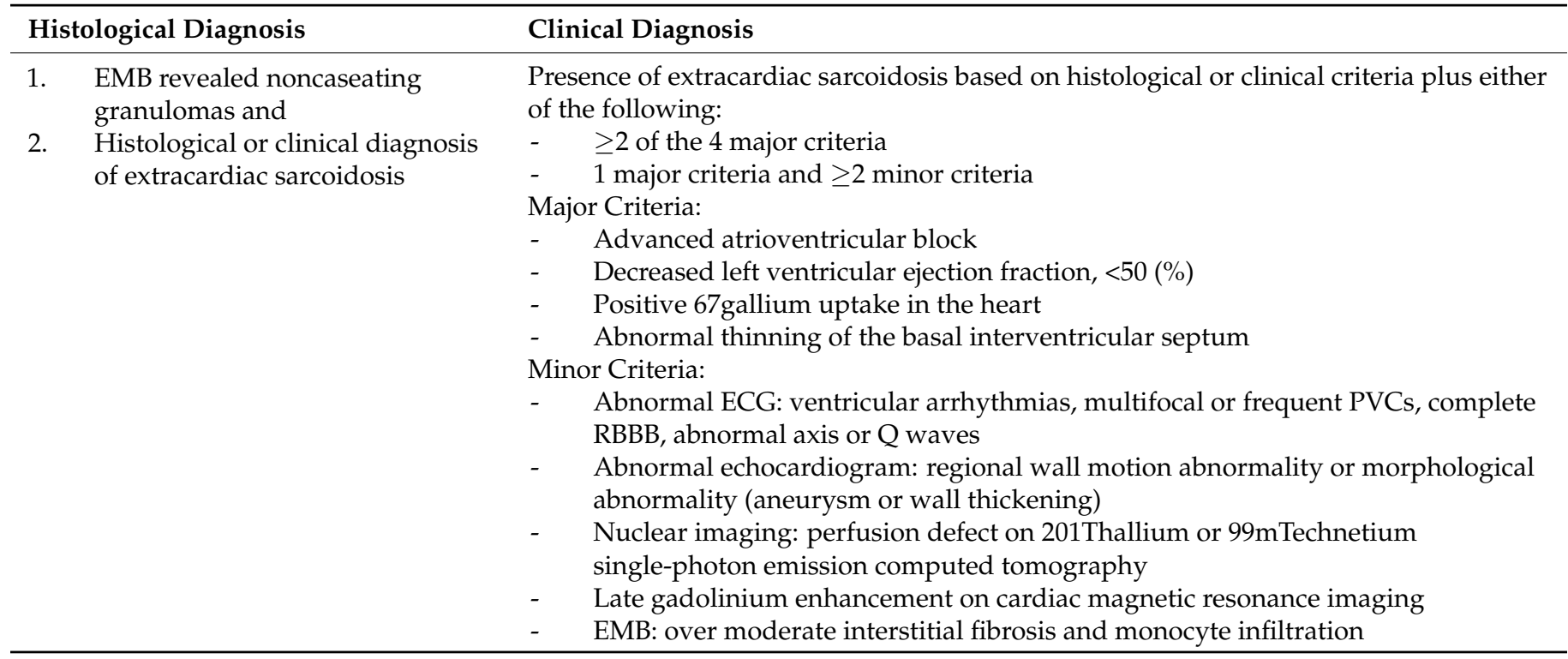

Abbreviations: EMB: endomyocardial biopsy; ECG: electrocardiogram: PVC: premature ventricular complex; RBBB: right bundle branch block. 
Table 5. Heart Rhythm Society expert consensus statements on criteria for diagnosing cardiac sarcoidosis [138].

\begin{tabular}{|c|c|}
\hline Histological Diagnosis & Clinical Diagnosis \\
\hline $\begin{array}{l}\text { 1. EMB revealed noncaseating } \\
\text { granulomas and }\end{array}$ & $\begin{array}{l}\text { It is probable cardiac sarcoidosis if: } \\
-\quad \text { There is presence of extracardiac sarcoidosis based on histological criteria }\end{array}$ \\
\hline $\begin{array}{l}\text { 2. Histological or clinical diagnosis } \\
\text { of extracardiac sarcoidosis }\end{array}$ & $\begin{array}{l}\text { And one or more of the following: } \\
\text { - } \quad \text { Treatment-responsive cardiomyopathy or heart block with corticosteroid } \\
\text { +/-immunosuppressant drug } \\
\text { - } \quad \text { Unexplained decreased left ventricular ejection fraction }<40(\%) \\
\text { - } \quad \text { Unexplained sustained ventricular tachycardia; spontaneous or induced } \\
\text { - } \quad \text { Mobitz type II second-degree heart block or complete heart block } \\
\quad \text { Patchy uptake of18F-flurodeoxyglycose on cardiac positron emission tomography, } \\
\text { typical pattern consistent with CS } \\
\text { - } \quad \text { Late gadolinium enhancement on cardiac magnetic resonance imaging, typical } \\
\text { pattern consistent with CS } \\
\text { - Positive gallium uptake on scintigraphy, typical pattern consistent with CS } \\
\text { AND: Other causes have been reasonably excluded }\end{array}$ \\
\hline
\end{tabular}

Abbreviations: CS: cardiac sarcoidosis; EMB: endomyocardial biopsy.

\subsubsection{Neurosarcoidosis}

An accurate diagnosis of neurosarcoidosis can also be challenging, as it requires histologic confirmation of the affected site and neural tissue is not easily accessible for pathologic examination. The Neurosarcoidosis Consortium Consensus recently proposed diagnostic criteria for central nervous system and peripheral nervous system neurosarcoidosis (Table 6) [209].

Table 6. Consensus Diagnostic Criteria for Neurosarcoidosis From the Neurosarcoidosis Consortium Consensus Group [209].

\section{Definite}

1. The clinical presentation and diagnostic evaluation suggest neurosarcoidosis, as defined by the clinical manifestations and MRI, CSF and/or EMG/NCS findings typical of granulomatous inflammation of the nervous system after rigorous exclusion of other causes

2. The nervous system pathology is consistent with neurosarcoidosis. Type a. Extraneural sarcoidosis is evident. Type b. No extraneural sarcoidosis is evident (isolated CNS sarcoidosis)

\section{Probable}

1. The clinical presentation and diagnostic evaluation suggest neurosarcoidosis, as defined by the clinical manifestations and MRI, CSF and/or EMG/NCS findings typical of granulomatous inflammation of the nervous system after rigorous exclusion of other causes

2. There is pathologic confirmation of systemic granulomatous disease consistent with sarcoidosis

\section{Possible}

1. The clinical presentation and diagnostic evaluation suggest neurosarcoidosis, as defined by the clinical manifestations and MRI, CSF and/or EMG/NCS findings typical of granulomatous inflammation of the nervous system and after rigorous exclusion of other causes

2. There is no pathologic confirmation of granulomatous disease.

Abbreviations: CNS: central nervous system; CSF: cerebrospinal fluid; EMG: electromyogram; MRI: magnetic resonance imaging; NCS: nerve conduction study.

\subsubsection{Ocular Sarcoidosis}

Biopsy is unacceptable for many patients with suspected sarcoidosis and uveitis. Therefore, a first International Workshop on Ocular Sarcoidosis (IWOS) criteria for the diagnosis of intraocular sarcoidosis have been published [210]. These criteria include a combination of suggestive ophthalmological findings and laboratory investigations when biopsy is not performed or negative. To overcome its low sensitivity, the revised IWOS criteria were recently established in an international consensus [211]. The survey and subsequent workshop reached consensus agreements on four criteria which are summarized in Table 7 [211]. The most substantial changes were the addition of four criteria: (1) 
lymphopenia; (2) CD4 alveolar lymphocytosis; (3) parenchymal lung changes consistent with sarcoidosis; and (4) abnormal label uptake on ${ }^{67} \mathrm{Ga}$ scintigraphy or ${ }^{18} \mathrm{~F}$-FDG PET CT.

Table 7. Revised criteria of International Workshop on Ocular Sarcoidosis (IWOS) for the diagnosis of ocular sarcoidosis (from [211]).

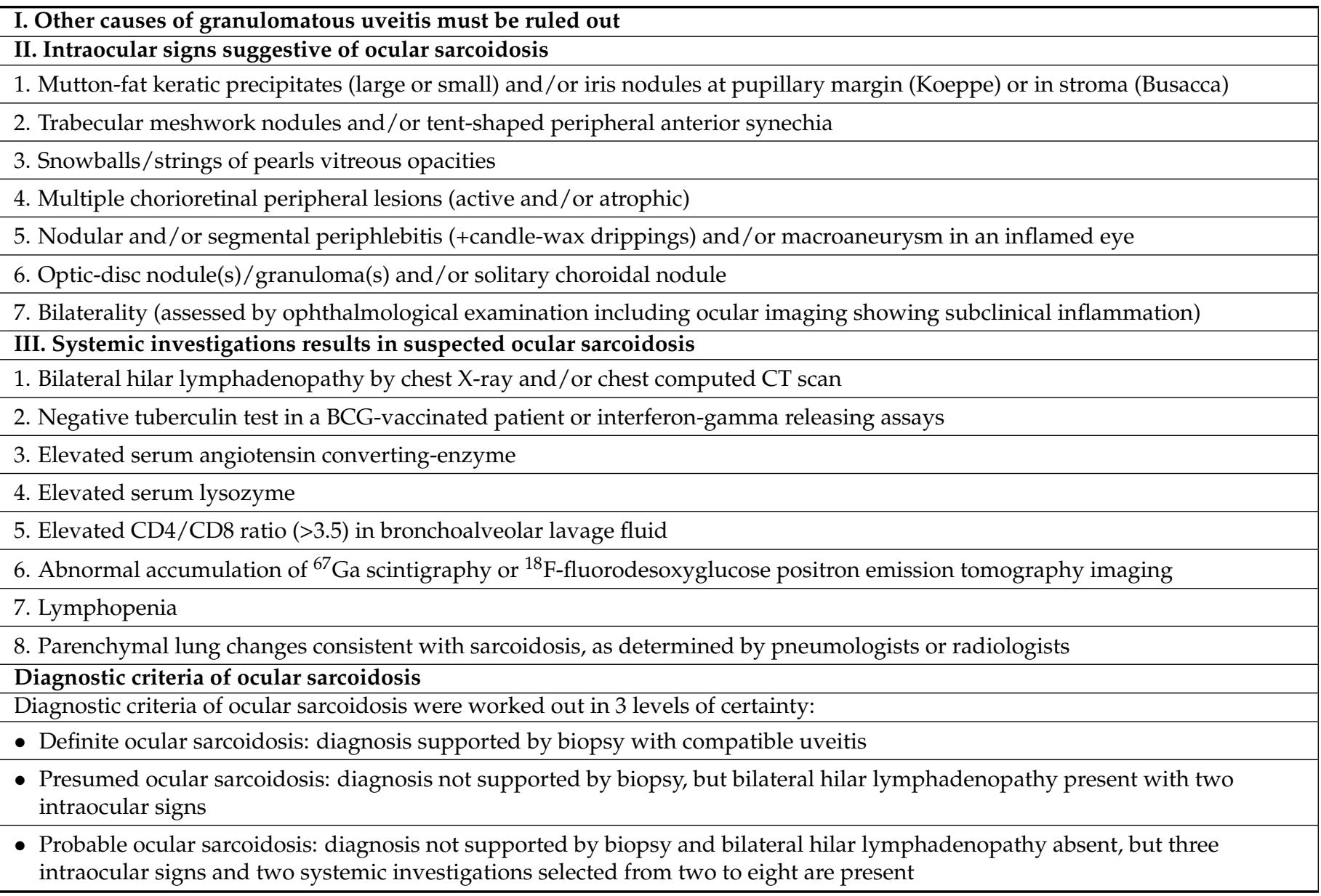

Abbreviations: CT: computed tomography.

\subsection{Histopathology}

Since the clinical manifestations of sarcoidosis are frequently non-specific, histological evidence of granulomas is often required to establish an accurate diagnosis. Sarcoidosic granulomas are composed of tightly clustered epithelioid histiocytes and occasionally multinucleated giant cells with few lymphocytes and often surrounded by fibrosis. An outer layer of loosely organized lymphocytes, mostly T cells, is often observed accompanied with few dendritic cells (Figure 10). In some cases, granulomas are surrounded by isolated collections of B-cells. Sarcoidosis granulomas are most of the time non-necrotizing. However, variants of sarcoidosis, particularly the nodular pulmonary sarcoidosis phenotype, can present with a mixture of necrotic (focal and usually minimal ischemic necrosis) and non-necrotic granulomas [212]. The differential diagnosis of granulomatous diseases is broad, as noted in the next section. Some histopathological features are not suggestive of sarcoidosis (e.g., few granulomas, loosely organized collections of mononuclear phagocytes/multinucleated giant cells, extensive necrosis, dirty necrosis (containing nuclear debris), palisading granulomas, lack of lymphatic distribution of granulomas, robust surrounding inflammatory infiltrate (including lymphocytes, neutrophils, eosinophils and plasma cells) andsecondary lymphoid follicles, although histopathologic features alone cannot distinguish sarcoidosis from other granulomatous diseases. Some granulomatous diseases may have similar histological features, such as berylliosis. 


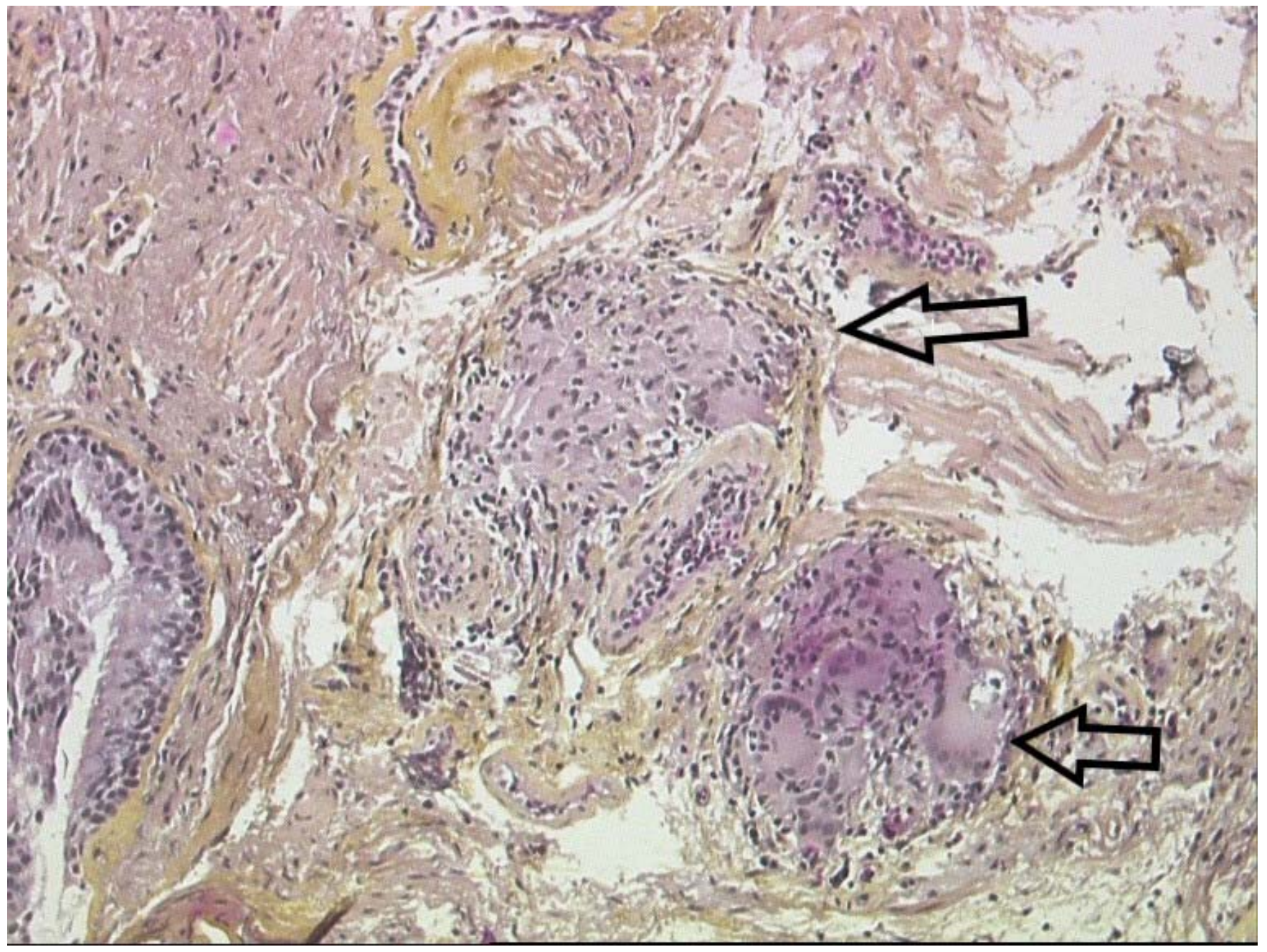

Figure 10. Lung biopsy: non-necrotizing epithelioid granulomas (arrows) with giant cells surrounding lymphocytes and fibrosis.

\section{Differential Diagnosis}

Many diseases can present with a sarcoidosis-like clinical phenotype (Table 8). Atypical manifestations that can make the diagnosis of sarcoidosis difficult are: hemoptysis, crackle rales, digital clubbing, unilateral hilar lymphadenopathy ( $3-5 \%$ of patients) or exclusive mediastinal lymphadenopathy without hilar lymph node enlargement, compressive lymphadenopathy, anterior mediastinal lymphadenopathy, miliary opacity, ground glass opacities, pleural involvement and bulky or cavitary mass (4\%) on chest imaging and hypogammaglobulinemia $[213,214]$. After initial diagnosis, the involvement of a new organ is rare and even more in the absence of residual disease activity [215]. Such unusual circumstances should question the responsibility of sarcoidosis and force the clinician to repeat histological sampling and microbiological analyses, including standard stains and cultures. Accurate pathological examination is also crucial in making the right diagnosis, as neoplastic disorders and especially lymphoma which can mimic sarcoidosis [216].

\subsection{Infectious Granulomatosis}

Tuberculosis is one of the main differential diagnosis of sarcoidosis but fortunately, some biological and histological elements can help distinguishing these entities [217]. Interferon $\gamma$-release assay (IGRA) has the same sensitivity as in the general population since anergy does not affect its performances contrary to tuberculin skin test [218]. Of note, IGRA is useful for latent tuberculous infection but useless in active tuberculosis. Mycobacterial-specific polymerase chain reactions, despite their low sensitivity may be 
useful to differentiate mycobacterial infections from sarcoidosis $[219,220]$. Atypical mycobacteria and histoplasmosis are also classical infectious differential diagnoses as well as Tropheryma whipplei infection.

Table 8. Main differential diagnoses to exclude in sarcoidosis (from [216]).

\begin{tabular}{ll}
\hline Sarcoidosis Subtype & Possible Differential Diagnosis \\
\hline & Tuberculosis and mycobacterial infections \\
& Hodgkin's disease and non Hodgkin's lymphoma \\
Mediastino pulmonary & Histoplasmosis, coccidioidomycosis, aspergillosis \\
sarcoidosis & Heumoconiosis: chronic beryllium disease, titanium, aluminium, talc \\
& Drug reactions \\
& Granulomatosis with polyangiitis, granulomatosis with eosinophilia and polyangiitis \\
\hline & Tuberculosis and mycobacterial infections \\
& Whipple disease, bartonellosis, Q fever, brucellosis, syphilis, toxoplasmosis, fungal infections \\
& Hodgkin disease and non Hodgkin's lymphoma \\
& Tumor associated sarcoid reaction \\
& Crohn's disease, primary biliary cirrhosis \\
& Drug induced sarcoidosis (interferon $\alpha$ and $\beta$, intravesical BCG therapy, TNF $\alpha$ inhibitors, \\
& immune check point inhibitors) \\
& Common variable immunodeficiency \\
\hline
\end{tabular}

\subsection{Other Inflammatory Diseases}

Granulomatosis with polyangiitis (GPA) and granulomatosis with eosinophilia and polyangiitis (EGPA) are differential diagnosis to keep in mind when the lungs are affected. In inflammatory bowel diseases and more specifically Crohn's disease, non-caseating granulomas are possible features all the more so as it could be associated with bronchiectasis [221].

\subsection{Drug Induced Granulomatosis}

Drug-induced sarcoid-like reactions (DISLR) are common during interferon therapy (especially with interferon alpha), which is known to induce granulomatous reactions with lung involvement in up to $76 \%$ of patients with hepatitis $C$ and granulomatosis [222]. DISLR have also been described with TNF inhibitors and especially with soluble TNF- $\alpha$ receptor etanercept [223]. Immune checkpoint inhibitors, such as anti-cytotoxic T-lymphocyteassociated protein 4 (CTLA4) antibodies (ipilimumab) and anti-programmed cell death protein 1 (PD1) (nivolumab, pembrolizumab) or anti-PDL1 (ligand) antibodies (atezolizumab, durvalumab, avelumab) can provoke DISLR. BRAF and MEK inhibitors (dabrafenib, vemurafenib and trametinib, cobimetinib) are also associated with sarcoidosis [224]. SLR occurring during cancer immunotherapy are usually associated with paucisymptomatic lung, skin and mediastinohilar involvement.

\subsection{Common Variable Immunodeficiency}

Hypogammaglobulinemia is unusual in sarcoidosis and should alert the clinical for potential differential diagnosis with common variable immunodeficiency (CVID). Systemic granulomatosis can occur in CVID. Nevertheless, Bouvry et al. observed differences in clinical, biological and imaging features comparing CVID-related granulomatous disease (CVID-RGD) and sarcoidosis. Patients with CVID-RGD were more likely to present with hepato- and splenomegaly compared to sarcoidosis patients and had also more frequently history of recurrent infections and autoimmune diseases (especially cytopenia). CD4/CD8 ratio in BAL fluid was significantly higher in sarcoidosis than in CVID-RGD patients. Chest $\mathrm{CT}$ patterns are also different: nodules and peribronchovascular micronodules are more common in sarcoidosis whereas nodules with halo sign were most seen in CVID-RGD patients [225]. 


\subsection{Neoplastic Disorders}

One should not miss cancer diagnosis when confronted to granulomatosis, as a wrong diagnosis and the induced delay in properly treating the underlying malignancy could be deleterious [226]. Sarcoidosis may precede, follow, or occur concomitantly with many cancers, especially lymphomas, making the differential between them a diagnostic challenge. Both cancer and sarcoidosis are ${ }^{18}$ F-FDG avid. Therefore, the ${ }^{18}$ F-FDG PET CT may be useful in selecting possible biopsy sites (in priority, sites with the most important 18-FDG uptake), but not in distinguishing between both entities. 18F-3'-Fluoro-3'-deoxythymidine PET CT can help to distinguish malignant from non-malignant lesions but its role in cancer is to be determined [227]. If uncertainty remains, multiple biopsies and repeated tissue sampling may be necessary to evidence malignant cells.

\subsection{Differential Diagnosis of Neurosarcoidosis}

A special attention should be paid to the differential diagnosis of neurosarcoidosis (Table 9). MRI is the preferred imaging technique to differentiate sarcoidosis from its main mimickers and especially multiple sclerosis [161]. Three different initial presentation can be separated: suspected neurosarcoidosis in the course of histologically proven sarcoidosis, a sarcoidosis history without evidence of disease activity and the case of a patient without known sarcoidosis history [180]. In the latter situation, as well as in a context of inactive sarcoidosis, the evidence of active sarcoidosis should be assessed and histological examination has to be obtained as far as possible before initiating a systemic treatment. As seen before, ${ }^{18} \mathrm{~F}$-FDG PET CT is of particular interest in those cases. If no evidence of active sarcoidosis can be found but the biopsy of any CNS structure reveals a sarcoid-like granulomatous reaction, one should be aware of the possible differential diagnosis between systemic neurosarcoidosis and a local sarcoid-like reaction, particularly related to an old neurological scar, neoplasia or an helminthic reaction [180].

Table 9. Main differential diagnosis of neurosarcoidosis (from $[180,228]$ ).

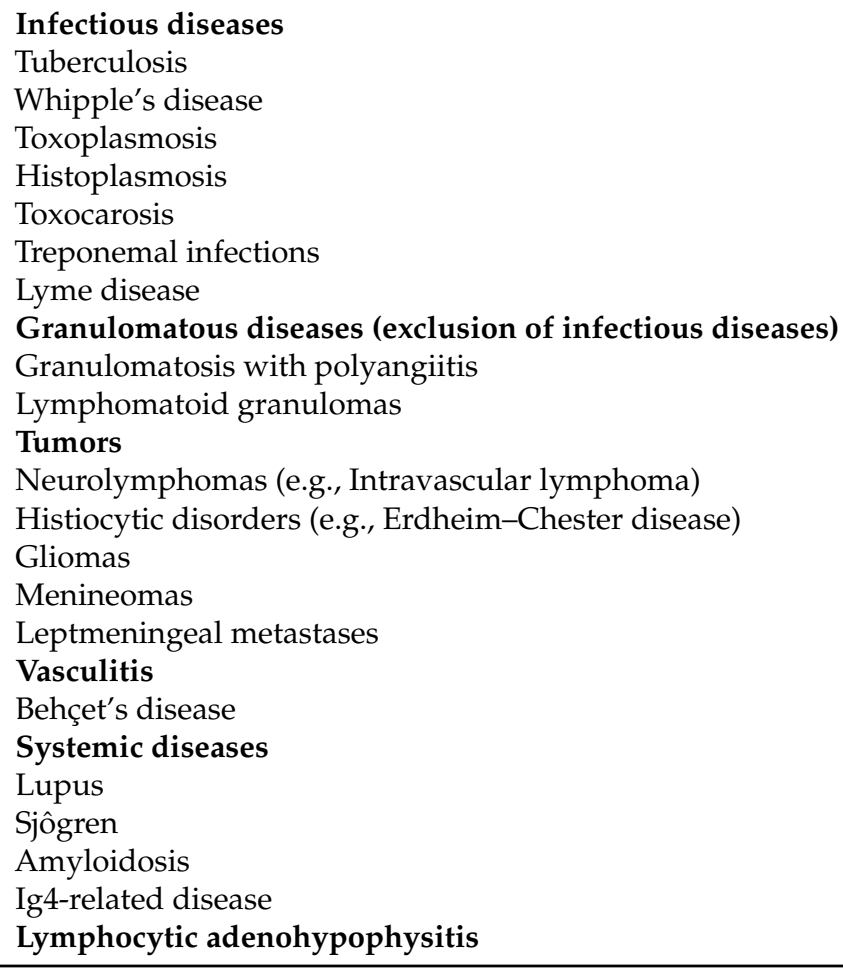


Table 9. Cont.

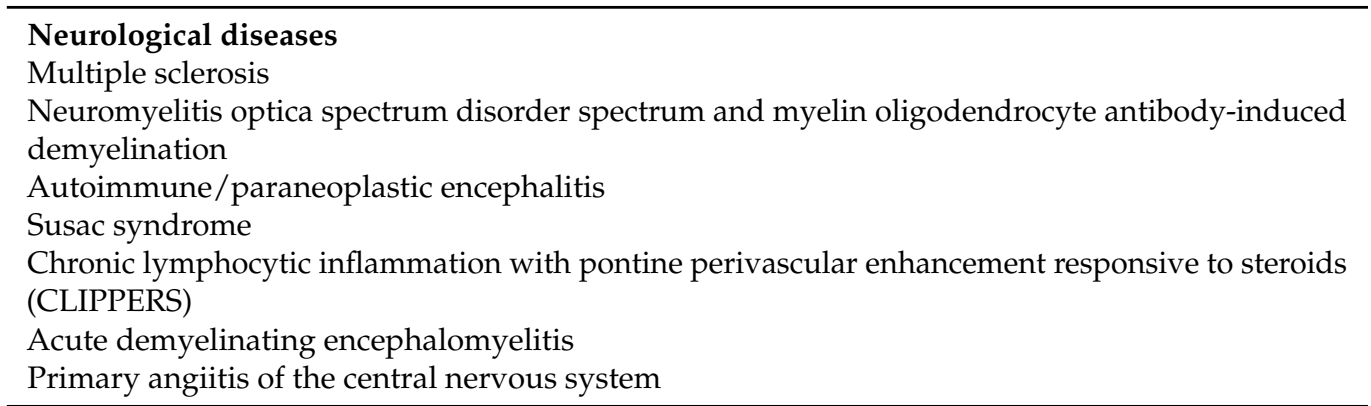

\section{Conclusions}

Sarcoidosis is susceptible to encompassing numerous different clinical presentations. Whether it is symptomatic or not, or acute or not, sarcoidosis can involve variable organs with a diverse clinical impact from benign to very severe. The diagnosis of sarcoidosis is based on three main criteria: a compatible presentation, the evidence of non-caseating granulomas on histological examination and the exclusion of any alternative diagnosis. However, even when all these criteria are fulfilled, the probability of sarcoidosis diagnosis varies from "definite" to only "possible" depending upon the presence of more or less characteristic, depending on radio-clinical and histopathological findings and on the epidemiological context. The main differential diagnosis includes infections, especially tuberculosis, and malignancies, especially lymphoma. Several studies have recently highlighted the existence of distinct phenotypes of sarcoidosis, with a non-random distribution of organ involvement, which are associated with sex, geographical origin and socio-professional category. Currently, these phenotypes should be used to understand sarcoidosis not as a single disease but as various syndromes. Genetic and environmental determinants of such phenotypes have to be elucidated in future studies to better understand the pathophysiology of sarcoidosis and eventually to guide the treatment.

Author Contributions: Conceptualization, P.S. and T.E.J.; methodology, P.S.; validation, P.S. and T.E.J.; writing—original draft preparation, P.S. and T.E.J.; writing—review and editing, P.S., T.E.J., F.D., G.A., Y.J., Y.P., M.G.-V., S.I., L.B., A.C., D.V. All authors have read and agreed to the published version of the manuscript.

Funding: This research received no external funding.

Acknowledgments: Diagrams were built with Lucidchart software on lucidchart.com.

Conflicts of Interest: The authors declare no conflict of interest related to this article.

\section{References}

1. Besnier, E.H. Lupus Pernio de La Face; Synovites Fongueuses (Scrofulo-Tuberculeuses) Symétriques Des Extrémités Supérieures. Ann. Derm. Syph. 1889, 10, 333-336.

2. Sakthivel, P.; Bruder, D. Mechanism of Granuloma Formation in Sarcoidosis. Curr. Opin. Hematol. 2017, 24, 59-65. [CrossRef] [PubMed]

3. Hunninghake, G.; Costabel, U. Statement on Sarcoidosis. Am. J. Respir. Crit. Care Med. 1999, 160, 20. [CrossRef]

4. Arkema, E.V.; Cozier, Y.C. Epidemiology of Sarcoidosis: Current Findings and Future Directions. Ther. Adv. Chronic Dis. 2018, 9, 227-240. [CrossRef] [PubMed]

5. Rybicki, B.A.; Major, M.; Popovich, J.; Maliank, M.J.; Lannuzzi, M.C. Racial Differences in Sarcoidosis Incidence: A 5-Year Study in a Health Maintenance Organization. Am. J. Epidemiol. 1997, 145, 234-241. [CrossRef] [PubMed]

6. Pereira, C.A.C.; Dornfeld, M.C.; Baughman, R.; Judson, M.A. Clinical Phenotypes in Sarcoidosis. Curr. Opin. Pulm. Med. 2014, 20, 496-502. [CrossRef] [PubMed]

7. Valeyre, D.; Prasse, A.; Nunes, H.; Uzunhan, Y.; Brillet, P.-Y.; Müller-Quernheim, J. Sarcoidosis. Lancet 2014, $383,1155-1167$. [CrossRef]

8. Nunes, H.; Bouvry, D.; Soler, P.; Valeyre, D. Sarcoidosis. Orphanet J. Rare Dis. 2007, 2, 46. [CrossRef] 
9. Nardi, A.; Brillet, P.-Y.; Letoumelin, P.; Girard, F.; Brauner, M.; Uzunhan, Y.; Naccache, J.-M.; Valeyre, D.; Nunes, H. Stage IV Sarcoidosis: Comparison of Survival with the General Population and Causes of Death. Eur. Respir. J. 2011, 38, $1368-1373$. [CrossRef]

10. Swigris, J.J.; Olson, A.L.; Huie, T.J.; Fernandez-Perez, E.R.; Solomon, J.; Sprunger, D.; Brown, K.K. Sarcoidosis-Related Mortality in the United States from 1988 to 2007. Am. J. Respir. Crit. Care Med. 2011, 183, 1524-1530. [CrossRef]

11. Kirkil, G.; Lower, E.E.; Baughman, R.P. Predictors of Mortality in Pulmonary Sarcoidosis. Chest 2018, 153, 105-113. [CrossRef]

12. Morimoto, T.; Azuma, A.; Abe, S.; Usuki, J.; Kudoh, S.; Sugisaki, K.; Oritsu, M.; Nukiwa, T. Epidemiology of Sarcoidosis in Japan. Eur. Respir. J. 2008, 31, 372-379. [CrossRef]

13. Jamilloux, Y.; Maucort-Boulch, D.; Kerever, S.; Gerfaud-Valentin, M.; Broussolle, C.; Eb, M.; Valeyre, D.; Seve, P. SarcoidosisRelated Mortality in France: A Multiple-Cause-of-Death Analysis. Eur. Respir. J. 2016, 48, 1700-1709. [CrossRef]

14. Baughman, R.P.; Teirstein, A.S.; Judson, M.A.; Rossman, M.D.; Yeager, H.; Bresnitz, E.A.; DePALO, L.; Hunninghake, G.; Iannuzzi, M.C.; Johns, C.J.; et al. Clinical Characteristics of Patients in a Case Control Study of Sarcoidosis. Am. J. Respir. Crit. Care Med. 2001, 164, 1885-1889. [CrossRef]

15. Ungprasert, P.; Carmona, E.M.; Utz, J.P.; Ryu, J.H.; Crowson, C.S.; Matteson, E.L. Epidemiology of Sarcoidosis 1946-2013. Mayo Clin. Proc. 2016, 91, 183-188. [CrossRef]

16. Mañá, J.; Rubio-Rivas, M.; Villalba, N.; Marcoval, J.; Iriarte, A.; Molina-Molina, M.; Llatjos, R.; García, O.; Martínez-Yélamos, S.; Vicens-Zygmunt, V.; et al. Multidisciplinary Approach and Long-Term Follow-up in a Series of 640 Consecutive Patients with Sarcoidosis: Cohort Study of a 40-Year Clinical Experience at a Tertiary Referral Center in Barcelona, Spain. Medicine 2017, 96, e7595. [CrossRef] [PubMed]

17. Valeyre, D.; Bernaudin, J.-F.; Jeny, F.; Duchemann, B.; Freynet, O.; Planès, C.; Kambouchner, M.; Nunes, H. Pulmonary Sarcoidosis. Clin. Chest Med. 2015, 36, 631-641. [CrossRef] [PubMed]

18. Judson, M.A. The Diagnosis of Sarcoidosis. Clin. Chest Med. 2008, 29, 415-427. [CrossRef]

19. Drent, M.; Strookappe, B.; Hoitsma, E.; De Vries, J. Consequences of Sarcoidosis. Clin. Chest Med. 2015, 36, 727-737. [CrossRef] [PubMed]

20. Drent, M.; Lower, E.E.; Vries, J.D. Sarcoidosis-Associated Fatigue. Eur. Respir. J. 2012, 40, 255-263. [CrossRef] [PubMed]

21. De Vries, J.; Michielsen, H.; Van Heck, G.L.; Drent, M. Measuring Fatigue in Sarcoidosis: The Fatigue Assessment Scale (FAS). Br. J. Health Psychol. 2004, 9, 279-291. [CrossRef] [PubMed]

22. Baughman, R.P.; Sparkman, B.K.; Lower, E.E. Six-Minute Walk Test and Health Status Assessment in Sarcoidosis. Chest 2007, 132, 207-213. [CrossRef]

23. Drent, M.; Wirnsberger, R.M.; de Vries, J.; van Dieijen-Visser, M.P.; Wouters, E.F.M.; Schols, A.M.W.J. Association of Fatigue with an Acute Phase Response in Sarcoidosis. Eur. Respir. J. 1999, 13, 718. [CrossRef] [PubMed]

24. Korenromp, I.H.E.; Heijnen, C.J.; Vogels, O.J.M.; van den Bosch, J.M.M.; Grutters, J.C. Characterization of Chronic Fatigue in Patients with Sarcoidosis in Clinical Remission. Chest 2011, 140, 441-447. [CrossRef] [PubMed]

25. Michielsen, H.J.; Drent, M.; Peros-Golubicic, T.; De Vries, J. Fatigue Is Associated with Quality of Life in Sarcoidosis Patients. Chest 2006, 130, 989-994. [CrossRef] [PubMed]

26. Elfferich, M.D.; Nelemans, P.J.; Ponds, R.W.; Vries, J.D.; Wijnen, P.A.; Drent, M. Everyday Cognitive Failure in Sarcoidosis: The Prevalence and the Effect of Anti-TNF- $\alpha$ Treatment. RES 2010, 80, 212-219. [CrossRef]

27. Crouser, E.D.; Maier, L.A.; Wilson, K.C.; Bonham, C.A.; Morgenthau, A.S.; Patterson, K.C.; Abston, E.; Bernstein, R.C.; Blankstein, R.; Chen, E.S.; et al. Diagnosis and Detection of Sarcoidosis. An Official American Thoracic Society Clinical Practice Guideline. Am. J. Respir. Crit. Care Med. 2020, 201, e26-e51. [CrossRef]

28. Telenti, A.; Hermans, P.E. Idiopathic Granulomatosis Manifesting as Fever of Unknown Origin. Mayo Clin. Proc. 1989, 64, 44-50. [CrossRef]

29. Iannuzzi, M.C.; Rybicki, B.A.; Teirstein, A.S. Sarcoidosis. N. Engl. J. Med. 2007, 357, 2153-2165. [CrossRef] [PubMed]

30. Judson, M.A.; Thompson, B.W.; Rabin, D.L.; Steimel, J.; Knattereud, G.L.; Lackland, D.T.; Rose, C.; Rand, C.S.; Baughman, R.P.; Teirstein, A.S. The Diagnostic Pathway to Sarcoidosis*. Chest 2003, 123, 406-412. [CrossRef]

31. Sinha, A.; Lee, K.K.; Rafferty, G.F.; Yousaf, N.; Pavord, I.D.; Galloway, J.; Birring, S.S. Predictors of Objective Cough Frequency in Pulmonary Sarcoidosis. Eur. Respir. J. 2016, 47, 1461-1471. [CrossRef]

32. Jeny, F.; Bernaudin, J.-F.; Cohen Aubart, F.; Brillet, P.-Y.; Bouvry, D.; Nunes, H.; Valeyre, D. Diagnosis Issues in Sarcoidosis. Respir. Med. Res. 2020, 77, 37-45. [CrossRef] [PubMed]

33. Jameson, A.; Revels, J.; Wang, L.L.; Wang, D.T.; Wang, S.S. Sarcoidosis, the Master Mimicker. Curr. Probl. Diagn. Radiol. 2020, S0363018820301973. [CrossRef]

34. Venkata Ramanan, R.; Pudhiavan, A.; Venkataramanan, A. The “Cluster of Black Pearls" Sign of Sarcoid Lymphadenopathy: A New Sign on Thin-Section Contrast-Enhanced Multidetector CT. Clin. Radiol. 2017, 72, 729-736. [CrossRef] [PubMed]

35. Martin, S.G.; Kronek, L.-P.; Valeyre, D.; Brauner, N.; Brillet, P.-Y.; Nunes, H.; Brauner, M.W.; Réty, F. High-Resolution Computed Tomography to Differentiate Chronic Diffuse Interstitial Lung Diseases with Predominant Ground-Glass Pattern Using Logical Analysis of Data. Eur. Radiol. 2010, 20, 1297-1310. [CrossRef] [PubMed]

36. Valeyre, D.; Bernaudin, J.-F.; Uzunhan, Y.; Kambouchner, M.; Brillet, P.-Y.; Soussan, M.; Nunes, H. Clinical Presentation of Sarcoidosis and Diagnostic Work-Up. Semin. Respir. Crit. Care Med. 2014, 35, 336-351. [CrossRef] 
37. Sharma, S.K.; Verma, U.; Pande, J.N.; Murugesan, K.; Verma, K.; Guleria, J.S. Glucocorticoid Receptors in Bronchoalveolar Lavage Fluid in Sarcoidosis. Chest 1988, 93, 577-579. [CrossRef] [PubMed]

38. Abehsera, M.; Valeyre, D.; Grenier, P.; Jaillet, H.; Battesti, J.P.; Brauner, M.W. Sarcoidosis with Pulmonary Fibrosis: CT Patterns and Correlation with Pulmonary Function. Am. J. Roentgenol. 2000, 174, 1751-1757. [CrossRef]

39. Lavergne, F.; Clerici, C.; Sadoun, D.; Brauner, M.; Battesti, J.-P.; Valeyre, D. Airway Obstruction in Bronchial Sarcoidosis. Chest 1999, 116, 1194-1199. [CrossRef]

40. Chambellan, A.; Turbie, P.; Nunes, H.; Brauner, M.; Battesti, J.-P.; Valeyre, D. Endoluminal Stenosis of Proximal Bronchi in Sarcoidosis. Chest 2005, 127, 472-481. [CrossRef]

41. Udwadia, Z.F.; Pilling, J.R.; Jenkins, P.F.; Harrison, B.D. Bronchoscopic and Bronchographic Findings in 12 Patients with Sarcoidosis and Severe or Progressive Airways Obstruction. Thorax 1990, 45, 272-275. [CrossRef]

42. Naccache, J.-M.; Lavolé, A.; Nunes, H.; Lamberto, C.; Letoumelin, P.; Brauner, M.; Valeyre, D.; Brillet, P.Y. High-Resolution Computed Tomographic Imaging of Airways in Sarcoidosis Patients With Airflow Obstruction. J. Comput. Assist. Tomogr. 2008, 32, 905-912. [CrossRef] [PubMed]

43. Wells, A.U.; Desai, S.R.; Rubens, M.B.; Goh, N.S.L.; Cramer, D.; Nicholson, A.G.; Colby, T.V.; du Bois, R.M.; Hansell, D.M. Idiopathic Pulmonary Fibrosis: A Composite Physiologic Index Derived from Disease Extent Observed by Computed Tomography. Am. J. Respir. Crit. Care Med. 2003, 167, 962-969. [CrossRef]

44. Walsh, S.L.; Wells, A.U.; Sverzellati, N.; Keir, G.J.; Calandriello, L.; Antoniou, K.M.; Copley, S.J.; Devaraj, A.; Maher, T.M.; Renzoni, E.; et al. An Integrated Clinicoradiological Staging System for Pulmonary Sarcoidosis: A Case-Cohort Study. Lancet Respir. Med. 2014, 2, 123-130. [CrossRef]

45. Delobbe, A.; Hélène, P.; Jocelyne, M.; Sophie, R.; Claude, H.-F.; Benoît, W.; Bernard, A. Impaired Exercise Response in Sarcoid Patients with Normal Pulmonary Function. Sarcoidosis Vasc. Diffus. Lung Dis. 2002, 19, 148-153.

46. Marcellis, R.G.J.; Lenssen, A.F.; de Vries, G.J.; Baughman, R.P.; van der Grinten, C.P.; Verschakelen, J.A.; De Vries, J.; Drent, M. Is There an Added Value of Cardiopulmonary Exercise Testing in Sarcoidosis Patients? Lung 2013, 191, 43-52. [CrossRef] [PubMed]

47. Wallaert, B.; Talleu, C.; Wemeau-Stervinou, L.; Duhamel, A.; Robin, S.; Aguilaniu, B. Reduction of Maximal Oxygen Uptake in Sarcoidosis: Relationship with Disease Severity. Respiration 2011, 82, 501-508. [CrossRef]

48. Lopes, A.J.; Menezes, S.L.S.; Dias, C.M.; Oliveira, J.F.; Mainenti, M.R.M.; Guimarães, F.S. Cardiopulmonary Exercise Testing Variables as Predictors of Long-Term Outcome in Thoracic Sarcoidosis. Braz. J. Med. Biol. Res. 2012, 45, 256-263. [CrossRef]

49. Kollert, F.; Geck, B.; Suchy, R.; Jörres, R.A.; Arzt, M.; Heidinger, D.; Hamer, O.W.; Prasse, A.; Müller-Quernheim, J.; Pfeifer, M.; et al. The Impact of Gas Exchange Measurement during Exercise in Pulmonary Sarcoidosis. Respir. Med. 2011, 105, 122-129. [CrossRef]

50. Costabel, U.; Bonella, F.; Ohshimo, S.; Guzman, J. Diagnostic Modalities in Sarcoidosis: BAL, EBUS, and PET. Semin. Respir. Crit. Care Med. 2010, 31, 404-408. [CrossRef]

51. Darlington, P.; Kullberg, S.; Eklund, A.; Grunewald, J. Subpopulations of Cells from Bronchoalveolar Lavage Can Predict Prognosis in Sarcoidosis. Eur. Respir. J. 2020, 55, 1901450. [CrossRef] [PubMed]

52. Mota, P.C.; Morais, A.; Palmares, C.; Beltrão, M.; Melo, N.; Santos, A.C.; Delgado, L. Diagnostic Value of CD103 Expression in Bronchoalveolar Lymphocytes in Sarcoidosis. Respir. Med. 2012, 106, 1014-1020. [CrossRef] [PubMed]

53. Heron, M.; Slieker, W.A.T.; Zanen, P.; van Lochem, E.G.; Hooijkaas, H.; van den Bosch, J.M.M.; van Velzen-Blad, H. Evaluation of CD103 as a Cellular Marker for the Diagnosis of Pulmonary Sarcoidosis. Clin. Immunol. 2008, 126, 338-344. [CrossRef]

54. Boucly, A.; Weatherald, J.; Savale, L.; Jaïs, X.; Cottin, V.; Prevot, G.; Picard, F.; de Groote, P.; Jevnikar, M.; Bergot, E.; et al. Risk Assessment, Prognosis and Guideline Implementation in Pulmonary Arterial Hypertension. Eur. Respir. J. 2017, 50, 1700889. [CrossRef] [PubMed]

55. Rubio-Rivas, M.; Franco, J.; Corbella, X. Sarcoidosis Presenting with and without Löfgren's Syndrome: Clinical, Radiological and Behavioral Differences Observed in a Group of 691 Patients. Jt. Bone Spine 2020, 87, 141-147. [CrossRef] [PubMed]

56. Karakaya, B.; Kaiser, Y.; van Moorsel, C.; Grunewald, J. Löfgren's Syndrome: Diagnosis, Management, and Disease Pathogenesis. Semin. Respir. Crit. Care Med. 2017, 38, 463-476. [CrossRef] [PubMed]

57. Goussault, C.; Albert, J.-D.; Coiffier, G.; Lamer, F.; Guillin, R.; Le Goff, B.; Bouvard, B.; Dernis, E.; Ferreyra, M.; Cormier, G.; et al. Ultrasound Characterization of Ankle Involvement in Löfgren Syndrome. Jt. Bone Spine 2018, 85, 65-69. [CrossRef] [PubMed]

58. Anandacoomarasamy, A.; Peduto, A.; Howe, G.; Maniolos, N.; Spencer, D. Magnetic Resonance Imaging in Löfgren's Syndrome: Demonstration of Periarthritis. Clin. Rheumatol. 2006, 26, 572-575. [CrossRef]

59. Cacciatore, C.; Belnou, P.; Thietart, S.; Desthieux, C.; Versini, M.; Abisror, N.; Ottaviani, S.; Cormier, G.; Deroux, A.; Dellal, A.; et al. Acute and Chronic Sarcoid Arthropathies: Characteristics and Treatments From a Retrospective Nationwide French Study. Front. Med. 2020, 7, 565420. [CrossRef]

60. Bechman, K.; Christidis, D.; Walsh, S.; Birring, S.S.; Galloway, J. A Review of the Musculoskeletal Manifestations of Sarcoidosis Rheumatology 2018, 57, 777-783. [CrossRef]

61. Sweiss, N.; Patterson, K.; Sawaqed, R.; Jabbar, U.; Korsten, P.; Hogarth, K.; Wollman, R.; Garcia, J.; Niewold, T.; Baughman, R. Rheumatologic Manifestations of Sarcoidosis. Semin. Respir. Crit. Care Med. 2010, 31, 463-473. [CrossRef]

62. Visser, H. Sarcoid Arthritis: Clinical Characteristics, Diagnostic Aspects, and Risk Factors. Ann. Rheum. Dis. 2002, 61, 499-504. [CrossRef] 
63. Kobak, S.; Sever, F.; Usluer, O.; Goksel, T.; Orman, M. The Clinical Characteristics of Sarcoid Arthropathy Based on a Prospective Cohort Study. Ther. Adv. Musculoskelet. Dis. 2016, 8, 220-224. [CrossRef] [PubMed]

64. Sukenik, S.; Hendler, N.; Yerushalmi, B.; Buskila, D.; Liberman, N. Jaccoud's-Type Arthropathy: An Association with Sarcoidosis. J. Rheumatol. 1991, 18, 915-917. [PubMed]

65. Erb, N.; Cushley, M.J.; Kassimos, D.G.; Shave, R.M.; Kitas, G.D. An Assessment of Back Pain and the Prevalence of Sacroiliitis in Sarcoidosis. Chest 2005, 127, 192-196. [CrossRef] [PubMed]

66. Sparks, J.A.; McSparron, J.I.; Shah, N.; Aliabadi, P.; Paulson, V.; Fanta, C.H.; Coblyn, J.S. Osseous Sarcoidosis: Clinical Characteristics, Treatment, and Outcomes-Experience from a Large, Academic Hospital. Semin. Arthritis Rheum. 2014, 44, 371-379. [CrossRef] [PubMed]

67. Mostard, R.L.; Prompers, L.; Weijers, R.E.; van Kroonenburgh, M.J.; Wijnen, P.A.; Geusens, P.P.; Drent, M. F-18 FDG PET/CT for Detecting Bone and Bone Marrow Involvement in Sarcoidosis Patients. Clin. Nucl. Med. 2012, 37, 21-25. [CrossRef] [PubMed]

68. Rúa-Figueroa, I.; Gantes, M.A.; Erausquin, C.; Mhaidli, H.; Montesdeoca, A. Vertebral Sarcoidosis: Clinical and Imaging Findings. Semin. Arthritis Rheum. 2002, 31, 346-352. [CrossRef]

69. Demaria, L.; Borie, R.; Benali, K.; Piekarski, E.; Goossens, G.; Palazzo, E.; Florien, M.; Dieudé, P.; Crestani, B.; Ottaviani, S. 18F-FDG PET/CT in Bone Sarcoidosis: An Observational Study. Clin. Rheumatol. 2020, 39, 2727-2734. [CrossRef]

70. Berger, C.; Sommer, C.; Meinck, H.-M. Isolated Sarcoid Myopathy. Muscle Nerve 2002, 26, 553-556. [CrossRef]

71. Douglas, A.C.; Macleod, J.G.; Matthews, J.D. Symptomatic Sarcoidosis of Skeletal Muscle. J. Neurol. Neurosurg. Psychiatry 1973, 36, 7. [CrossRef]

72. Silverstein, A.; Siltzbach, L.E. Muscle Involvement in Sarcoidosis. Arch. Neurol. 1969, 21, 7. [CrossRef]

73. Wolfe, S.M.; Pinals, R.S.; Aelion, J.A.; Goodman, R.E. Myopathy in Sarcoidosis: Clinical and Pathologic Study of Four Cases and Review of the Literature. Semin. Arthritis Rheum. 1987, 16, 300-306. [CrossRef]

74. Cremers, J.P.; Van Kroonenburgh, M.J.; Mostard, R.L.; Vöö, S.A.; Wijnen, P.A.; Koek, G.H.; Drent, M. Extent of Disease Activity Assessed by 18F-FDG PET/CT in a Dutch Sarcoidosis Population. Sarcoidosis Vasc. Diffus. Lung Dis. 2014, $31,37-45$.

75. Roux, K.L.; Streichenberger, N.; Vial, C.; Petiot, P.; Feasson, L.; Bouhour, F.; Ninet, J.; Lachenal, F.; Broussolle, C.; Sève, P. Granulomatous Myositis: A Clinical Study of Thirteen Cases. Muscle Nerve 2007, 35, 171-177. [CrossRef]

76. Androdias, G.; Maillet, D.; Marignier, R.; Pinede, L.; Confavreux, C.; Broussolle, C.; Vukusic, S.; Seve, P. Mycophenolate Mofetil May Be Effective in CNS Sarcoidosis but Not in Sarcoid Myopathy. Neurology 2011, 76, 1168-1172. [CrossRef]

77. Dieudonné, Y.; Allenbach, Y.; Benveniste, O.; Leonard-Louis, S.; Hervier, B.; Mariampillai, K.; Nespola, B.; Lannes, B.; EchanizLaguna, A.; Wendling, D.; et al. Granulomatosis-Associated Myositis: High Prevalence of Sporadic Inclusion Body Myositis. Neurology 2020, 94, e910-e920. [CrossRef] [PubMed]

78. Ungprasert, P.; Crowson, C.S.; Matteson, E.L. Influence of Gender on Epidemiology and Clinical Manifestations of Sarcoidosis: A Population-Based Retrospective Cohort Study 1976-2013. Lung 2017, 195, 87-91. [CrossRef]

79. James, D.G.; Neville, E.; Siltzbach, L.E.; Turiaf, J.; Battesti, J.P.; Sharma, O.P.; Hosoda, Y.; Mikami, R.; Odaka, M.; Villar, T.G.; et al. A Worldwide Review of Sarcoidosis*. Ann. N. Y. Acad. Sci. 1976, 278, 321-334. [CrossRef] [PubMed]

80. Studdy, P.R.; Bird, R.; Neville, E.; James, D.G. Biochemical Findings in Sarcoidosis. J. Clin. Pathol. 1980, 33, 528-533. [CrossRef] [PubMed]

81. Baughman, R.P.; Janovcik, J.; Ray, M.; Sweiss, N.; Lower, E.E. Calcium and Vitamin D Metabolism in Sarcoidosis. Sarcoidosis Vasc. Diffus. Lung Dis. 2013, 30, 113-120.

82. Gwadera, Ł.; Białas, A.J.; Iwański, M.A.; Górski, P.; Piotrowski, W.J. Sarcoidosis and Calcium Homeostasis Disturbances-Do We Know Where We Stand? Chron. Respir. Dis. 2019, 16. [CrossRef]

83. Adams, J.S. Vitamin D Metabolite-Mediated Hypercalcemia. Endocrinol. Metab. Clin. N. Am. 1989, 18, 765-778. [CrossRef]

84. Caplan, A.; Rosenbach, M.; Imadojemu, S. Cutaneous Sarcoidosis. Semin. Respir. Crit. Care Med. 2020, 41, 689-699. [CrossRef] [PubMed]

85. Marcoval, J.; Mañá, J.; Rubio, M. Specific Cutaneous Lesions in Patients with Systemic Sarcoidosis: Relationship to Severity and Chronicity of Disease. Clin. Exp. Dermatol. 2011, 36, 739-744. [CrossRef] [PubMed]

86. Haimovic, A.; Sanchez, M.; Judson, M.A.; Prystowsky, S. Sarcoidosis: A Comprehensive Review and Update for the Dermatologist. J. Am. Acad. Dermatol. 2012, 66, 719.e1-719.e10. [CrossRef] [PubMed]

87. Bodaghi, B.; Touitou, V.; Fardeau, C.; Chapelon, C.; LeHoang, P. Ocular Sarcoidosis. La Presse Médicale 2012, 41, e349-e354. [CrossRef]

88. Jamilloux, Y.; Kodjikian, L.; Broussolle, C.; Sève, P. Sarcoidosis and Uveitis. Autoimmun. Rev. 2014, 13, 840-849. [CrossRef]

89. Coulon, C.; Kodjikian, L.; Rochepeau, C.; Perard, L.; Jardel, S.; Burillon, C.; Broussolle, C.; Jamilloux, Y.; Seve, P. Ethnicity and Association with Ocular, Systemic Manifestations and Prognosis in 194 Patients with Sarcoid Uveitis. Graefes Arch. Clin. Exp. Ophthalmol. 2019, 257, 2495-2503. [CrossRef]

90. Birnbaum, A.D.; French, D.D.; Mirsaeidi, M.; Wehrli, S. Sarcoidosis in the National Veteran Population. Ophthalmology 2015, 122, 934-938. [CrossRef]

91. Pasadhika, S.; Rosenbaum, J.T. Ocular Sarcoidosis. Clin. Chest Med. 2015, 36, 669-683. [CrossRef] [PubMed]

92. Ma, S.P.; Rogers, S.L.; Hall, A.J.; Hodgson, L.; Brennan, J.; Stawell, R.J.; Lim, L.L. Sarcoidosis-Related Uveitis: Clinical Presentation, Disease Course, and Rates of Systemic Disease Progression After Uveitis Diagnosis. Am. J. Ophthalmol. 2019, 198, 30-36. [CrossRef] [PubMed] 
93. Greenberg, G.; Anderson, R.; Sharpstone, P.; James, D.G. Enlargement of Parotid Gland Due to Sarcoidosis. Br. Med. J. 1964, 2, 861-862. [CrossRef] [PubMed]

94. Darlington, P.; Tallstedt, L.; Padyukov, L.; Kockum, I.; Cederlund, K.; Eklund, A.; Grunewald, J. HLA-DRB1* Alleles and Symptoms Associated with Heerfordt's Syndrome in Sarcoidosis. Eur. Respir. J. 2011. [CrossRef] [PubMed]

95. Heerfordt, C. Über Eine 'Febris Uveoparotidea Subchronica' an Der Glandula Parotis Der Uvea Des Auges Lokalisiert Und Häufig Mit Paresen Cerebrospinaler Nerver Kompliziert. Arch. Ophthalmol. 1909, 70, 254-273.

96. Makimoto, G.; Kawakado, K.; Nakanishi, M.; Tamura, T.; Noda, M.; Makimoto, S.; Sato, Y.; Kuyama, S. Heerfordt's Syndrome Associated with Trigeminal Nerve Palsy and Reversed Halo Sign. Intern. Med. 2020. [CrossRef]

97. Mikulic, S.; Patel, P.; Sheffield, S.; Kandah, F.; Velarde, G. Heerfordt-Waldenström Syndrome Manifesting as Cardiac Sarcoidosis Cureus 2020, 12, e10619. [CrossRef]

98. Rochepeau, C.; Jamilloux, Y.; Kerever, S.; Febvay, C.; Perard, L.; Broussolle, C.; Burillon, C.; Kodjikian, L.; Seve, P. Long-Term Visual and Systemic Prognoses of 83 Cases of Biopsy-Proven Sarcoid Uveitis. Br. J. Ophthalmol. 2017, 101, 856-861. [CrossRef]

99. Sève, P.; Jamilloux, Y.; Tilikete, C.; Gerfaud-Valentin, M.; Kodjikian, L.; El Jammal, T. Ocular Sarcoidosis. Semin. Respir. Crit. Care Med. 2020, 41, 673-688. [CrossRef]

100. Paovic, J.; Paovic, P.; Sredovic, V.; Jovanovic, S. Clinical Manifestations, Complications and Treatment of Ocular Sarcoidosis: Correlation between Visual Efficiency and Macular Edema as Seen on Optical Coherence Tomography. Semin. Ophthalmol. 2016, 1-8. [CrossRef] [PubMed]

101. Miserocchi, E.; Modorati, G.; Di Matteo, F.; Galli, L.; Rama, P.; Bandello, F. Visual Outcome in Ocular Sarcoidosis: Retrospective Evaluation of Risk Factors. Eur. J. Ophthalmol. 2011, 21, 802-810. [CrossRef]

102. Dana, M.-R.; Merayo-Lloves, J.; Schaumberg, D.A.; Foster, C.S. Prognosticators for Visual Outcome in Sarcoid Uveitis. Ophthalmology 1996, 103, 1846-1853. [CrossRef]

103. Rothova, A. Ocular Involvement in Sarcoidosis. Br. J. Ophthalmol. 2000, 84, 110-116. [CrossRef] [PubMed]

104. Koczman, J.J.; Rouleau, J.; Gaunt, M.; Kardon, R.H.; Wall, M.; Lee, A.G. Neuro-Ophthalmic Sarcoidosis: The University of Iowa Experience. Semin. Ophthalmol. 2008, 23, 157-168. [CrossRef]

105. Prabhakaran, V.C.; Saeed, P.; Esmaeli, B.; Sullivan, T.J.; McNab, A.; Davis, G.; Valenzuela, A.; Leibovitch, I.; Kesler, A.; SivakCallcott, J.; et al. Orbital and Adnexal Sarcoidosis. Arch. Ophthalmol. 2007, 125, 1657-1662. [CrossRef] [PubMed]

106. Braswell, R.A.; Kline, L.B. Neuro-Ophthalmologic Manifestations of Sarcoidosis. Int. Ophthalmol. Clin. 2007, 47, 67-77. [CrossRef]

107. Leclercq, M.; Langlois, V.; Girszyn, N.; Le Besnerais, M.; Benhamou, Y.; Levesque, H.; Muraine, M.; Gueudry, J. Comparison of Conventional Immunosuppressive Drugs versus Anti-TNF- $\alpha$ Agents in Non-Infectious Non-Anterior Uveitis. J. Autoimmun. 2020, 113, 102481. [CrossRef]

108. Tadros, M.; Forouhar, F.; Wu, G.Y. Hepatic Sarcoidosis. J. Clin. Transl. Hepatol. 2013, 1, 87-93. [CrossRef]

109. Deutsch-Link, S.; Fortuna, D.; Weinberg, E.M. A Comprehensive Review of Hepatic Sarcoid. Semin. Liver Dis. 2018, 38, 284-297. [CrossRef]

110. Judson, M. Extrapulmonary Sarcoidosis. Semin. Respir. Crit. Care Med. 2007, 28, 083-101. [CrossRef] [PubMed]

111. Bihari, C.; Rastogi, A.; Kumar, N.; Rajesh, S.; Sarin, S.K. Hepatic Sarcoidosis: Clinico-Pathological Characterization of Symptomatic Cases. Acta Gastroenterol. Belg. 2015, 78, 306-313.

112. Moreno-Merlo, F.; Wanless, I.R.; Shimamatsu, K.; Sherman, M.; Greig, P.; Chiasson, D. The Role of Granulomatous Phlebitis and Thrombosis in the Pathogenesis of Cirrhosis and Portal Hypertension in Sarcoidosis. Hepatology 1997, 26, 554-560. [CrossRef] [PubMed]

113. Alam, I.; Levenson, S.D.; Ferrell, L.D.; Bass, N.M. Diffuse Intrahepatic Biliary Strictures in Sarcoidosis Resembling Sclerosing Cholangitis (Case Report and Review of the Literature). Dig. Dis. Sci. 1997, 42, 1295-1301. [CrossRef] [PubMed]

114. Delfosse, V.; de Leval, L.; De Roover, A.; Delwaide, J.; Honoré, P.; Boniver, J.; Detry, O. Budd-Chiari Syndrome Complicating Hepatic Sarcoidosis: Definitive Treatment by Liver Transplantation: A Case Report. Transplant. Proc. 2009, 41, 3432-3434. [CrossRef] [PubMed]

115. Ungprasert, P.; Crowson, C.S.; Simonetto, D.A.; Matteson, E.L. Clinical Characteristics and Outcome of Hepatic Sarcoidosis: A Population-Based Study 1976-2013. Am. J. Gastroenterol. 2017, 112, 1556-1563. [CrossRef]

116. Warshauer, D.M.; Dumbleton, S.A.; Molina, P.L.; Yankaskas, B.C.; Parker, L.A.; Woosley, J.T. Abdominal CT Findings in Sarcoidosis: Radiologic and Clinical Correlation. Radiology 1994, 192, 93-98. [CrossRef] [PubMed]

117. Ungprasert, P.; Ryu, J.H.; Matteson, E.L. Clinical Manifestations, Diagnosis, and Treatment of Sarcoidosis. Mayo Clin. Proc. Innov. Qual. Outcomes 2019, 3, 358-375. [CrossRef]

118. Syed, U.; Alkhawam, H.; Bakhit, M.; Companioni, R.A.C.; Walfish, A. Hepatic Sarcoidosis: Pathogenesis, Clinical Context, and Treatment Options. Scand. J. Gastroenterol. 2016, 51, 1025-1030. [CrossRef]

119. Coash, M.; Forouhar, F.; Wu, C.H.; Wu, G.Y. Granulomatous Liver Diseases: A Review. J. Formos. Med. Assoc. 2012, 111, 3-13. [CrossRef] [PubMed]

120. Lagana, S.M.; Moreira, R.K.; Lefkowitch, J.H. Hepatic Granulomas: Pathogenesis and Differential Diagnosis. Clin. Liver Dis. 2010, 14, 605-617. [CrossRef]

121. Gaya, D.R. Hepatic Granulomas: A 10 Year Single Centre Experience. J. Clin. Pathol. 2003, 56, 850-853. [CrossRef]

122. Geri, G.; Cacoub, P. Granulomatose hépatique. Rev. Méd. Interne 2011, 32, 560-566. [CrossRef] [PubMed]

123. Wainwright, H. Hepatic Granulomas. Eur. J. Gastroenterol. Hepatol. 2007, 19, 93-95. [CrossRef] 
124. Esfeh, J.M.; Culver, D.; Plesec, T.; John, B. Clinical Presentation and Protocol for Management of Hepatic Sarcoidosis. Expert Rev. Gastroenterol. Hepatol. 2015, 9, 349-358. [CrossRef]

125. Britt, A.R.; Francis, I.R.; Glazer, G.M.; Ellis, J.H. Sarcoidosis: Abdominal Manifestations at CT. Radiology 1991, 178, 91-94. [CrossRef]

126. Folz, S.J.; Johnson, C.D.; Swensen, S.J. Abdominal Manifestations of Sarcoidosis in CT Studies. J. Comput. Assist. Tomogr. 1995, 19, 573-579. [CrossRef] [PubMed]

127. Warshauer, D.M.; Molina, P.L.; Hamman, S.M.; Koehler, R.E.; Paulson, E.K.; Bechtold, R.E.; Perlmutter, M.L.; Hiken, J.N.; Francis, I.R.; Cooper, C.J. Nodular Sarcoidosis of the Liver and Spleen: Analysis of 32 Cases. Radiology 1995, 195, 757-762. [CrossRef] [PubMed]

128. Tetikkurt, C.; Yanardag, H.; Pehlivan, M.; Bilir, M. Clinical Features and Prognostic Significance of Splenic Involvement in Sarcoidosis. Monaldi Arch. Chest Dis. 2017, 87. [CrossRef] [PubMed]

129. Warshauer, D.M.; Lee, J.K.T. Imaging Manifestations of Abdominal Sarcoidosis. Am. J. Roentgenol. 2004, 182, 15-28. [CrossRef] [PubMed]

130. Tana, C.; Donatiello, I.; Coppola, M.G.; Ricci, F.; Maccarone, M.T.; Ciarambino, T.; Cipollone, F.; Giamberardino, M.A. CT Findings in Pulmonary and Abdominal Sarcoidosis. Implications for Diagnosis and Classification. J. Clin. Med. 2020, 9, 3028. [CrossRef]

131. Ghrenassia, E.; Mekinian, A.; Chapelon-Albric, C.; Levy, P.; Cosnes, J.; Sève, P.; Lefèvre, G.; Dhôte, R.; Launay, D.; Prendki, V.; et al. Digestive-Tract Sarcoidosis: French Nationwide Case-Control Study of 25 Cases. Medicine 2016, 95, e4279. [CrossRef]

132. Munker, M.; Sharma, O.P. Fatal Gastrointestinal Haemorrhage in Sarcoidosis: A Previously Unreported Occurrence. Sarcoidosis 1987, 4, 55-57. [PubMed]

133. Inomata, M.; Ikushima, S.; Awano, N.; Kondoh, K.; Satake, K.; Masuo, M.; Moriya, A.; Kamiya, H.; Ando, T.; Azuma, A.; et al. Upper Gastrointestinal Sarcoidosis: Report of Three Cases. Intern. Med. 2012, 51, 1689-1694. [CrossRef] [PubMed]

134. Rubio-Rivas, M.; Corbella, X. Clinical Phenotypes and Prediction of Chronicity in Sarcoidosis Using Cluster Analysis in a Prospective Cohort of 694 Patients. Eur. J. Intern. Med. 2020, 77, 59-65. [CrossRef] [PubMed]

135. Schupp, J.C.; Freitag-Wolf, S.; Bargagli, E.; Mihailović-Vučinić, V.; Rottoli, P.; Grubanovic, A.; Müller, A.; Jochens, A.; Tittmann, L.; Schnerch, J.; et al. Phenotypes of Organ Involvement in Sarcoidosis. Eur. Respir. J. 2018, 51, 1700991. [CrossRef]

136. Chapelon-Abric, C.; De Zuttere, D.; Duhaut, P.; Veyssier, P.; Wechsler, B.; Huong, D.L.T.; De Gennes, C.; Papo, T.; Blétry, O.; Godeau, P.; et al. Cardiac Sarcoidosis: A Retrospective Study of 41 Cases. Medicine 2004, 83, 315-334. [CrossRef]

137. Han, Y.S.; Rivera-Grana, E.; Salek, S.; Rosenbaum, J.T. Distinguishing Uveitis Secondary to Sarcoidosis From Idiopathic Disease: Cardiac Implications. Jama Ophthalmol. 2018, 136, 109. [CrossRef]

138. Birnie, D.H.; Sauer, W.H.; Bogun, F.; Cooper, J.M.; Culver, D.A.; Duvernoy, C.S.; Judson, M.A.; Kron, J.; Mehta, D.; Cosedis Nielsen, J.; et al. HRS Expert Consensus Statement on the Diagnosis and Management of Arrhythmias Associated with Cardiac Sarcoidosis. Heart Rhythm. 2014, 11, 1304-1323. [CrossRef]

139. Mehta, D.; Lubitz, S.A.; Frankel, Z.; Wisnivesky, J.P.; Einstein, A.J.; Goldman, M.; Machac, J.; Teirstein, A. Cardiac Involvement in Patients with Sarcoidosis: Diagnostic and Prognostic Value of Outpatient Testing. Chest 2008, 133, 1426-1435. [CrossRef]

140. Kouranos, V.; Tzelepis, G.E.; Rapti, A.; Mavrogeni, S.; Aggeli, K.; Douskou, M.; Prasad, S.; Koulouris, N.; Sfikakis, P.; Wells, A.; et al. Complementary Role of CMR to Conventional Screening in the Diagnosis and Prognosis of Cardiac Sarcoidosis. JACC Cardiovasc. Imaging 2017, 10, 1437-1447. [CrossRef]

141. Silverman, K.J.; Hutchins, G.M.; Bulkley, B.H. Cardiac Sarcoid: A Clinicopathologic Study of 84 Unselected Patients with Systemic Sarcoidosis. Circulation 1978, 58, 1204-1211. [CrossRef]

142. Iwai, K.; Tachibana, T.; Takemura, T.; Matsui, Y.; Kitalchi, M.; Kawabata, Y. Pathological Studies on Sarcoidosis Autopsy. I. Epidemiological Features of 320 Cases in Japan. Pathol. Int. 1993, 43, 372-376. [CrossRef]

143. Nunes, H.; Freynet, O.; Naggara, N.; Soussan, M.; Weinman, P.; Diebold, B.; Brillet, P.-Y.; Valeyre, D. Cardiac Sarcoidosis. Semin. Respir. Crit. Care Med. 2010, 31, 428-441. [CrossRef]

144. Kandolin, R.; Lehtonen, J.; Airaksinen, J.; Vihinen, T.; Miettinen, H.; Ylitalo, K.; Kaikkonen, K.; Tuohinen, S.; Haataja, P.; Kerola, T.; et al. Cardiac Sarcoidosis: Epidemiology, Characteristics, and Outcome over 25 Years in a Nationwide Study. Circulation 2015, 131, 624-632. [CrossRef]

145. Ribeiro Neto, M.L.; Jellis, C.L.; Joyce, E.; Callahan, T.D.; Hachamovitch, R.; Culver, D.A. Update on Cardiac Sarcoidosis. Ann. Am. Thorac. Soc. 2019. [CrossRef] [PubMed]

146. Zhou, Y.; Lower, E.E.; Li, H.-P.; Costea, A.; Attari, M.; Baughman, R.P. Cardiac Sarcoidosis: The Impact of Age and Implanted Devices on Survival. Chest 2017, 151, 139-148. [CrossRef] [PubMed]

147. Kurmann, R. Echocardiography in Sarcoidosis. Curr. Cardiol. Rep. 2018, 20, 118. [CrossRef] [PubMed]

148. Terasaki, F.; Yoshinaga, K. New Guidelines for Diagnosis of Cardiac Sarcoidosis in Japan. Ann. Nucl. Cardiol. 2017, 3, 42-45. [CrossRef]

149. Murtagh, G.; Laffin, L.J.; Beshai, J.F.; Maffessanti, F.; Bonham, C.A.; Patel, V.A.; Yu, Z.; Addetia, K.; Mor-Avi, V.; Moss, J.D.; et al. Prognosis of Myocardial Damage in Sarcoidosis Patients with Preserved Left Ventricular Ejection Fraction: Risk Stratification Using Cardiovascular Magnetic Resonance. Circ. Cardiovasc. Imaging 2016, 9, 1-9. [CrossRef]

150. Hulten, E.; Agarwal, V.; Cahill, M.; Cole, G.; Vita, T.; Parrish, S.; Bittencourt, M.S.; Murthy, V.L.; Kwong, R.; Di Carli, M.F.; et al. Presence of Late Gadolinium Enhancement by Cardiac Magnetic Resonance Among Patients With Suspected Cardiac Sarcoidosis Is Associated With Adverse Cardiovascular Prognosis. Circ. Cardiovasc. Imaging 2016, 9, 139-148. [CrossRef] 
151. Nadel, J.; Lancefield, T.; Voskoboinik, A.; Taylor, A.J. Late Gadolinium Enhancement Identified with Cardiacmagnetic Resonance Imaging in Sarcoidosis Patients Is Associated with Long-Term Ventricular Arrhythmia and Sudden Cardiac Death. Eur. Heart J. Cardiovasc. Imaging 2015, 16, 634-641. [CrossRef]

152. Shafee, M.A.; Fukuda, K.; Wakayama, Y.; Nakano, M.; Kondo, M.; Hasebe, Y.; Kawana, A.; Shimokawa, H. Delayed Enhancement on Cardiac Magnetic Resonance Imaging Is a Poor Prognostic Factor in Patients with Cardiac Sarcoidosis. J. Cardiol. 2012, 60, 448-453. [CrossRef]

153. Vita, T.; Okada, D.R.; Veillet-Chowdhury, M.; Bravo, P.E.; Mullins, E.; Hulten, E.; Agrawal, M.; Madan, R.; Taqueti, V.R.; Steigner, M.; et al. Complementary Value of Cardiac Magnetic Resonance Imaging and Positron Emission Tomography/Computed Tomography in the Assessment of Cardiac Sarcoidosis. Circ. Cardiovasc. Imaging 2018, 11, e007030. [CrossRef] [PubMed]

154. Birnie, D.; Beanlands, R.S.B.; Nery, P.; Aaron, S.D.; Culver, D.A.; DeKemp, R.A.; Gula, L.; Ha, A.; Healey, J.S.; Inoue, Y.; et al. Cardiac Sarcoidosis Multi-Center Randomized Controlled Trial (CHASM CS- RCT). Am. Heart J. 2020, 220, 246-252. [CrossRef] [PubMed]

155. Ardehali, H.; Howard, D.L.; Hariri, A.; Qasim, A.; Hare, J.M.; Baughman, K.L.; Kasper, E.K. A Positive Endomyocardial Biopsy Result for Sarcoid Is Associated with Poor Prognosis in Patients with Initially Unexplained Cardiomyopathy. Am. Heart J. 2005, 150, 459-463. [CrossRef] [PubMed]

156. Fritz, D.; van de Beek, D.; Brouwer, M.C. Clinical Features, Treatment and Outcome in Neurosarcoidosis: Systematic Review and Meta-Analysis. BMC Neurol. 2016, 16, 220. [CrossRef]

157. Cação, G.; Branco, A.; Meireles, M.; Alves, J.E.; Mateus, A.; Silva, A.M.; Santos, E. Neurosarcoidosis According to Zajicek and Scolding Criteria: 15 Probable and Definite Cases, Their Treatment and Outcomes. J. Neurol. Sci. 2017, 379, 84-88. [CrossRef]

158. Kidd, D.P. Neurosarcoidosis: Clinical Manifestations, Investigation and Treatment. Pract. Neurol. 2020, 20, 199-212. [CrossRef]

159. Ungprasert, P.; Crowson, C.S.; Matteson, E.L. Characteristics and Long-Term Outcome of Neurosarcoidosis: A Population-Based Study from 1976-2013. Neuroepidemiology 2017, 48, 87-94. [CrossRef]

160. Ungprasert, P.; Matteson, E.L. Neurosarcoidosis. Rheum. Dis. Clin. N. Am. 2017, 43, 593-606. [CrossRef]

161. Culver, D.A.; Neto, M.L.R.; Moss, B.P.; Willis, M.A. Neurosarcoidosis. Semin. Respir. Crit. Care Med. 2017, 38, 499-513. [CrossRef]

162. Joubert, B.; Chapelon-Abric, C.; Biard, L.; Saadoun, D.; Demeret, S.; Dormont, D.; Resche-Rigon, M.; Cacoub, P. Association of Prognostic Factors and Immunosuppressive Treatment With Long-Term Outcomes in Neurosarcoidosis. JAMA Neurol. 2017, 74, 1336-1344. [CrossRef]

163. Bridel, C.; Courvoisier, D.S.; Vuilleumier, N.; Lalive, P.H. Cerebrospinal Fluid Angiotensin-Converting Enzyme for Diagnosis of Neurosarcoidosis. J. Neuroimmunol. 2015, 285, 1-3. [CrossRef]

164. Arun, T.; Pattison, L.; Palace, J. Distinguishing Neurosarcoidosis from Multiple Sclerosis Based on CSF Analysis: A Retrospective Study. Neurology 2020, 94, e2545-e2554. [CrossRef] [PubMed]

165. Chazal, T.; Costopoulos, M.; Maillart, E.; Fleury, C.; Psimaras, D.; Legendre, P.; Pineton de Chambrun, M.; Haroche, J.; Lubetzki, C.; Amoura, Z.; et al. The Cerebrospinal Fluid CD4/CD8 Ratio and Interleukin-6 and -10 Levels in Neurosarcoidosis: A Multicenter, Pragmatic, Comparative Study. Eur. J. Neurol. 2019, 26, 1274-1280. [CrossRef] [PubMed]

166. Stern, B.J.; Aksamit, A.; Clifford, D.; Scott, T.F. Neurosarcoidosis Study Group Neurologic Presentations of Sarcoidosis. Neurol. Clin. 2010, 28, 185-198. [CrossRef] [PubMed]

167. Scott, T.F.; Yandora, K.; Valeri, A.; Chieffe, C.; Schramke, C. Aggressive Therapy for Neurosarcoidosis: Long-Term Follow-up of 48 Treated Patients. Arch. Neurol. 2007, 64, 691-696. [CrossRef] [PubMed]

168. Bogousslavsky, J.; Hungerbühler, J.P.; Regli, F.; Graf, H.J. Subacute Myelopathy as the Presenting Manifestation of Sarcoidosis. Acta Neurochir. 1982, 65, 193-197. [CrossRef] [PubMed]

169. Durel, C.-A.; Marignier, R.; Maucort-Boulch, D.; Iwaz, J.; Berthoux, E.; Ruivard, M.; André, M.; Le Guenno, G.; Pérard, L.; Dufour, J.-F.; et al. Clinical Features and Prognostic Factors of Spinal Cord Sarcoidosis: A Multicenter Observational Study of 20 BIOPSY-PROVEN Patients. J. Neurol. 2016, 263, 981-990. [CrossRef] [PubMed]

170. Spencer, T.S.; Campellone, J.V.; Maldonado, I.; Huang, N.; Usmani, Q.; Reginato, A.J. Clinical and Magnetic Resonance Imaging Manifestations of Neurosarcoidosis. Semin. Arthritis Rheum. 2005, 34, 649-661. [CrossRef]

171. Murphy, O.; Salazar-Camelo, A.; Jimenez, J.; Barreras, P.; Reyes, M.; Garcia, M.; Moller, D.; Chen, E.; Pardo, C. Clinical and MRI Phenotypes of Sarcoidosis-Associated Myelopathy. Neurol. Neuroimmunol. Neuroinflamm. 2020, 7, e722. [CrossRef]

172. Freda, P.U.; Post, K.D. Differential Diagnosis of Sellar Masses. Endocrinol. Metab. Clin. N. Am. 1999, 28, 81-117. [CrossRef]

173. Langrand, C.; Bihan, H.; Raverot, G.; Varron, L.; Androdias, G.; Borson-Chazot, F.; Brue, T.; Cathebras, P.; Pinede, L.; Muller, G.; et al. Hypothalamo-Pituitary Sarcoidosis: A Multicenter Study of 24 Patients. QJM 2012, 105, 981-995. [CrossRef]

174. Tavee, J.O.; Karwa, K.; Ahmed, Z.; Thompson, N.; Parambil, J.; Culver, D.A. Sarcoidosis-Associated Small Fiber Neuropathy in a Large Cohort: Clinical Aspects and Response to IVIG and Anti-TNF Alpha Treatment. Respir. Med. 2017, 126, 135-138. [CrossRef] [PubMed]

175. Hoitsma, E.; Reulen, J.P.H.; de Baets, M.; Drent, M.; Spaans, F.; Faber, C.G. Small Fiber Neuropathy: A Common and Important Clinical Disorder. J. Neurol. Sci. 2004, 227, 119-130. [CrossRef] [PubMed]

176. Parambil, J.G.; Tavee, J.O.; Zhou, L.; Pearson, K.S.; Culver, D.A. Efficacy of Intravenous Immunoglobulin for Small Fiber Neuropathy Associated with Sarcoidosis. Respir. Med. 2011, 105, 101-105. [CrossRef]

177. Hoitsma, E.; De Vries, J.; Drent, M. The Small Fiber Neuropathy Screening List: Construction and Cross-Validation in Sarcoidosis. Respir. Med. 2011, 105, 95-100. [CrossRef] 
178. Hebel, R.; Dubaniewicz-Wybieralska, M.; Dubaniewicz, A. Overview of Neurosarcoidosis: Recent Advances. J. Neurol. 2015, 262, 258-267. [CrossRef]

179. Colvin, I.B. Audiovestibular Manifestations of Sarcoidosis: A Review of the Literature. Laryngoscope 2006, 116, 75-82. [CrossRef]

180. Hoitsma, E.; Faber, C.G.; Drent, M.; Sharma, O.P. Neurosarcoidosis: A Clinical Dilemma. Lancet Neurol 2004, 3, 397-407. [CrossRef]

181. Burns, T.M.; Dyck, P.J.B.; Aksamit, A.J.; Dyck, P.J. The Natural History and Long-Term Outcome of 57 Limb Sarcoidosis Neuropathy Cases. J. Neurol. Sci. 2006, 244, 77-87. [CrossRef] [PubMed]

182. Jachiet, V.; Lhote, R.; Rufat, P.; Pha, M.; Haroche, J.; Crozier, S.; Dupel-Potier, C.; Psimaras, D.; Amoura, Z.; Cohen Aubart, F. Clinical, Imaging, and Histological Presentations and Outcomes of Stroke Related to Sarcoidosis. J. Neurol. 2018, 265, $2333-2341$. [CrossRef]

183. Mahévas, M.; Lescure, F.X.; Boffa, J.-J.; Delastour, V.; Belenfant, X.; Chapelon, C.; Cordonnier, C.; Makdassi, R.; Piette, J.-C.; Naccache, J.-M.; et al. Renal Sarcoidosis: Clinical, Laboratory, and Histologic Presentation and Outcome in 47 Patients. Medicine 2009, 88, 98-106. [CrossRef]

184. Cozier, Y.C.; Berman, J.S.; Palmer, J.R.; Boggs, D.A.; Serlin, D.M.; Rosenberg, L. Sarcoidosis in Black Women in the United States: Data from the Black Women's Health Study. Chest 2011, 139, 144-150. [CrossRef] [PubMed]

185. Judson, M.A.; Boan, A.D.; Lackland, D.T. The Clinical Course of Sarcoidosis: Presentation, Diagnosis, and Treatment in a Large White and Black Cohort in the United States. Sarcoidosis Vasc. Diffus. Lung Dis. 2012, 29, 119-127.

186. Kamata, Y.; Sato, H.; Joh, K.; Tsuchiya, Y.; Kunugi, S.; Shimizu, A.; Konta, T.; Baughman, R.P.; Azuma, A. Clinical Characteristics of Biopsy-Proven Renal Sarcoidosis in Japan. Sarcoidosis Vasc. Diffus. Lung Dis. 2018, 35, 252-260. [CrossRef]

187. Javaud, N.; Belenfant, X.; Stirnemann, J.; Laederich, J.; Ziol, M.; Callard, P.; Ronco, P.; Rondeau, E.; Fain, O. Renal Granulomatoses: A Retrospective Study of 40 Cases and Review of the Literature. Medicine 2007, 86, 170-180. [CrossRef] [PubMed]

188. Shah, S.; Carter-Monroe, N.; Atta, M.G. Granulomatous Interstitial Nephritis. Clin. Kidney J. 2015, 8, 516-523. [CrossRef]

189. Clive, D.M.; Vanguri, V.K. The Syndrome of Tubulointerstitial Nephritis With Uveitis (TINU). Am. J. Kidney Dis. 2018, 72, 118-128. [CrossRef]

190. Bergner, R.; Hoffmann, M.; Waldherr, R.; Uppenkamp, M. Frequency of Kidney Disease in Chronic Sarcoidosis. Sarcoidosis Vasc. Diffus. Lung Dis. 2003, 20, 126-132.

191. Bergner, R.; Löffler, C. Renal Sarcoidosis: Approach to Diagnosis and Management. Curr. Opin. Pulm. Med. 2018, 24, 513-520. [CrossRef]

192. Mrówka-Kata, K.; Kata, D.; Lange, D.; Namysłowski, G.; Czecior, E.; Banert, K. Sarcoidosis and Its Otolaryngological Implications. Eur. Arch. Oto-Rhino-Laryngol. Off. J. Eur. Fed. Oto-Rhino-Laryngol. Soc. (Eufos) Affil. Ger. Soc. Oto-Rhino-Laryngol. Head Neck Surg. 2010, 267, 1507-1514. [CrossRef] [PubMed]

193. Aubart, F.C.; Ouayoun, M.; Brauner, M.; Attali, P.; Kambouchner, M.; Valeyre, D.; Nunes, H. Sinonasal Involvement in Sarcoidosis: A Case-Control Study of 20 Patients. Medicine 2006, 85, 365-371. [CrossRef] [PubMed]

194. Lawson, W.; Jiang, N.; Cheng, J. Sinonasal Sarcoidosis: A New System of Classification Acting as a Guide to Diagnosis and Treatment. Am. J. Rhinol. Allergy 2014, 28, 317-322. [CrossRef] [PubMed]

195. Edriss, H.; Kelley, J.S.; Demke, J.; Nugent, K. Sinonasal and Laryngeal Sarcoidosis—An Uncommon Presentation and Management Challenge. Am. J. Med. Sci. 2019, 357, 93-102. [CrossRef]

196. Duchemann, B.; Lavolé, A.; Naccache, J.-M.; Nunes, H.; Benzakin, S.; Lefevre, M.; Kambouchner, M.; Périé, S.; Valeyre, D.; Cadranel, J. Laryngeal Sarcoidosis: A Case-Control Study. Sarcoidosis Vasc. Diffus. Lung Dis. 2014, 31, $227-234$.

197. Rotman, A.; Maughan, E.F.; Rouhani, M.J.; Holroyd, A.; Ashcroft, M.; Al Yaghchi, C.; Sandhu, G. Laryngeal Sarcoidosis at a Tertiary Airway Centre: Our Experience with 32 Patients. Clin. Otolaryngol. 2020. [CrossRef]

198. Lhote, R.; Annesi-Maesano, I.; Nunes, H.; Launay, D.; Borie, R.; Sacré, K.; Schleinitz, N.; Hamidou, M.; Mahevas, M.; Devilliers, H.; et al. Clinical Phenotypes of Extrapulmonary Sarcoidosis: An Analysis of a French, Multiethnic, Multicenter Cohort. Eur. Respir. J. 2020, 2001160. [CrossRef]

199. Kreider, M.E.; Christie, J.D.; Thompson, B.; Newman, L.; Rose, C.; Barnard, J.; Bresnitz, E.; Judson, M.A.; Lackland, D.T.; Rossman, M.D. Relationship of Environmental Exposures to the Clinical Phenotype of Sarcoidosis. Chest 2005, 128, 207-215. [CrossRef]

200. Judson, M.A.; Costabel, U.; Drent, M.; Wells, A.; Maier, L.; Koth, L.; Shigemitsu, H.; Culver, D.A.; Gelfand, J.; Valeyre, D.; et al. The WASOG Sarcoidosis Organ Assessment Instrument: An Update of a Previous Clinical Tool. Sarcoidosis Vasc. Diffus. Lung Dis. 2014, 31, 19-27.

201. Bickett, A.N.; Lower, E.E.; Baughman, R.P. Sarcoidosis Diagnostic Score. Chest 2018, 154, 1052-1060. [CrossRef]

202. Agrawal, A.; Ghori, U.; Chaddha, U.; Murgu, S. Combined EBUS-IFB and EBUS-TBNA vs. EBUS-TBNA Alone for Intrathoracic Adenopathy: A Meta-Analysis. Ann. Thorac. Surg. 2021. [CrossRef] [PubMed]

203. Bernard, C.; Kodjikian, L.; Bancel, B.; Isaac, S.; Broussolle, C.; Seve, P. Ocular Sarcoidosis: When Should Labial Salivary Gland Biopsy Be Performed? Graefes Arch. Clin. Exp. Ophthalmol. 2013, 251, 855-860. [CrossRef]

204. Blaise, P.; Fardeau, C.; Chapelon, C.; Bodaghi, B.; Le Hoang, P. Minor Salivary Gland Biopsy in Diagnosing Ocular Sarcoidosis. Br. J. Ophthalmol. 2011, 95, 1731-1734. [CrossRef] [PubMed]

205. Keijsers, R.G.M.; Grutters, J.C. In Which Patients with Sarcoidosis Is FDG PET/CT Indicated? J. Clin. Med. 2020, 9, 890. [CrossRef] [PubMed] 
206. Rahmi, A.; Deshayes, E.; Maucort-Boulch, D.; Varron, L.; Grange, J.D.; Kodjikian, L.; Seve, P. Intraocular Sarcoidosis: Association of Clinical Characteristics of Uveitis with Findings from ${ }^{18}$ F-Labelled Fluorodeoxyglucose Positron Emission Tomography. Br. J. Ophthalmol. 2012, 96, 99-103. [CrossRef] [PubMed]

207. Tan, J.L.; Fong, H.K.; Birati, E.Y.; Han, Y. Cardiac Sarcoidosis. Am. J. Cardiol. 2019, 123, 513-522. [CrossRef] [PubMed]

208. Yoshinaga, K.; Miyagawa, M.; Kiso, K.; Ishida, Y. Japanese Guidelines for Cardiac Sarcoidosis. Ann. Nucl. Cardiol. 2017, 3, 121-124. [CrossRef]

209. Stern, B.J.; Royal, W.; Gelfand, J.M.; Clifford, D.B.; Tavee, J.; Pawate, S.; Berger, J.R.; Aksamit, A.J.; Krumholz, A.; Pardo, C.A.; et al. Definition and Consensus Diagnostic Criteria for Neurosarcoidosis: From the Neurosarcoidosis Consortium Consensus Group. JAMA Neurol. 2018, 75, 1546. [CrossRef] [PubMed]

210. Herbort, C.P.; Rao, N.A.; Mochizuki, M. The members of the Scientific Commi International Criteria for the Diagnosis of Ocular Sarcoidosis: Results of the First International Workshop on Ocular Sarcoidosis (IWOS). Ocul. Immunol. Inflamm. 2009, 17, 160-169. [CrossRef]

211. Mochizuki, M.; Smith, J.R.; Takase, H.; Kaburaki, T.; Acharya, N.R.; Rao, N.A. Revised Criteria of International Workshop on Ocular Sarcoidosis (IWOS) for the Diagnosis of Ocular Sarcoidosis. Br. J. Ophthalmol. 2019, 103, 1418-1422. [CrossRef]

212. Rosen, Y. Four Decades of Necrotizing Sarcoid Granulomatosis: What Do We Know Now? Arch. Pathol. Lab. Med. 2015, 139, 252-262. [CrossRef]

213. Criado, E.; Sánchez, M.; Ramírez, J.; Arguis, P.; de Caralt, T.M.; Perea, R.J.; Xaubet, A. Pulmonary Sarcoidosis: Typical and Atypical Manifestations at High-Resolution CT with Pathologic Correlation. RadioGraphics 2010, 30, 1567-1586. [CrossRef]

214. Park, H.J.; Jung, J.I.; Chung, M.H.; Song, S.W.; Kim, H.L.; Baik, J.H.; Han, D.H.; Kim, K.J.; Lee, K.-Y. Typical and Atypical Manifestations of Intrathoracic Sarcoidosis. Korean J. Radiol. 2009, 10, 623. [CrossRef]

215. Spagnolo, P.; Luppi, F.; Roversi, P.; Cerri, S.; Fabbri, L.M.; Richeldi, L. Sarcoidosis: Challenging Diagnostic Aspects of an Old Disease. Am. J. Med. 2012, 125, 118-125. [CrossRef]

216. El Jammal, T.; Jamilloux, Y.; Gerfaud-Valentin, M.; Valeyre, D.; Sève, P. Refractory Sarcoidosis: A Review. TCRM 2020, 16, 323-345. [CrossRef] [PubMed]

217. Gousseff, M.; Mechaï, F.; Lecuit, M.; Lortholary, O. Les granulomatoses systémiques d'origine infectieuse. La Rev. De Médecine Interne 2008, 29, 15-27. [CrossRef]

218. Piotrowski, W.J.; Żąłło, P.P.L.J.; Górski, W.; Kumor-Kisielewska, A.; Fijałkowski, M.; Kurmanowska, Z.; Marczak, J.; Gwadera, Ł.; Angowski, W.; Górski, P.; et al. QuantiFERON-TB-GOLD In-Tube in Patients with Sarcoidosis. Adv. Respir. Med. 2018 , 86, $234-239$. [CrossRef] [PubMed]

219. O'Sullivan, C.E.; Miller, D.R.; Schneider, P.S.; Roberts, G.D. Evaluation of Gen-Probe Amplified Mycobacterium Tuberculosis Direct Test by Using Respiratory and Nonrespiratory Specimens in a Tertiary Care Center Laboratory. J. Clin. Microbiol. 2002, 40, 1723-1727. [CrossRef] [PubMed]

220. Dhooria, S.; Gupta, N.; Bal, A. Role of Xpert MTB/RIF in Differentiating Tuberculosis from Sarcoidosis in Patients with Mediastinal Lymphadenopathy Undergoing EBUS-TBNA: A Study of 147 Patients. Sarcoidosis Vasc. Diffus. Lung Dis. 2016, 33, $258-266$.

221. Ohshimo, S.; Guzman, J.; Costabel, U.; Bonella, F. Differential Diagnosis of Granulomatous Lung Disease: Clues and Pitfalls: Number 4 in the Series "Pathology for the Clinician" Edited by Peter Dorfmüller and Alberto Cavazza. Eur. Respir. Rev. 2017, 26, 170012. [CrossRef] [PubMed]

222. Ramos-Casals, M.; Mañá, J.; Nardi, N.; Brito-Zerón, P.; Xaubet, A.; Sánchez-Tapias, J.M.; Cervera, R.; Font, J. Sarcoidosis in Patients With Chronic Hepatitis C Virus Infection: Analysis of 68 Cases. Medicine 2005, 84, 69-80. [CrossRef] [PubMed]

223. Chopra, A.; Nautiyal, A.; Kalkanis, A.; Judson, M.A. Drug-Induced Sarcoidosis-Like Reactions. Chest 2018, 154 , 664-677. [CrossRef] [PubMed]

224. Cohen Aubart, F.; Lhote, R.; Amoura, A.; Valeyre, D.; Haroche, J.; Amoura, Z.; Lebrun-Vignes, B. Drug-induced Sarcoidosis: An Overview of the WHO Pharmacovigilance Database. J. Intern. Med. 2019. [CrossRef] [PubMed]

225. Bouvry, D.; Mouthon, L.; Brillet, P.-Y.; Kambouchner, M.; Ducroix, J.-P.; Cottin, V.; Haroche, J.; Viallard, J.-F.; Lazor, R.; Lebargy, F.; et al. Granulomatosis-Associated Common Variable Immunodeficiency Disorder: A Case-Control Study versus Sarcoidosis. Eur. Respir. J. 2013, 41, 115-122. [CrossRef]

226. El Jammal, T.; Pavic, M.; Gerfaud-Valentin, M.; Jamilloux, Y.; Seve, P. Sarcoidosis and Cancer: A Complex Relationship. Front. Med. 2020. Accepted for publication. [CrossRef]

227. Lococo, F.; Muoio, B.; Chiappetta, M.; Nachira, D.; Petracca Ciavarella, L.; Margaritora, S.; Treglia, G. Diagnostic Performance of PET or PET/CT with Different Radiotracers in Patients with Suspicious Lung Cancer or Pleural Tumours According to Published Meta-Analyses. Contrast Media Mol. Imaging 2020, 2020, 1-7. [CrossRef]

228. Law, L.Y.; Riminton, D.S.; Nguyen, M.; Barnett, M.H.; Reddel, S.W.; Hardy, T.A. The Spectrum of Immune-Mediated and Inflammatory Lesions of the Brainstem: Clues to Diagnosis. Neurology 2019, 93, 390-405. [CrossRef] 